Article

\title{
Surface Oxidation of Supported Ni Particles and Its Impact on the Catalytic Performance during Dynamically Operated Methanation of $\mathrm{CO}_{2}$
}

\author{
Benjamin Mutz ${ }^{1,2}$, Andreas Martin Gänzler ${ }^{1}$, Maarten Nachtegaal ${ }^{3}$, Oliver Müller ${ }^{4,5}$, \\ Ronald Frahm ${ }^{4}$, Wolfgang Kleist 1,2,6 and Jan-Dierk Grunwaldt 1,2,* (D) \\ 1 Institute for Chemical Technology and Polymer Chemistry, Karlsruhe Institute of Technology (KIT), \\ D-76131 Karlsruhe, Germany; benjamin.mutz@kit.edu (B.M.); andreas.gaenzler@kit.edu (A.M.G.); \\ wolfgang.kleist@rub.de (W.K.) \\ 2 Institute of Catalysis Research and Technology, Karlsruhe Institute of Technology (KIT), \\ D-76344 Eggenstein-Leopoldshafen, Germany \\ 3 Paul Scherrer Institute (PSI), CH-5232 Villigen, Switzerland; maarten.nachtegaal@psi.ch \\ 4 Department of Physics, University of Wuppertal, D-42119 Wuppertal, Germany; \\ omueller@slac.stanford.edu (O.M.); frahm@uni-wuppertal.de (R.F.) \\ 5 Stanford Synchrotron Radiation Lightsource (SSRL), SLAC National Accelerator Laboratory, \\ Menlo Park, CA 94025, USA \\ 6 Laboratory of Industrial Chemistry, Ruhr-University Bochum, D-44801 Bochum, Germany \\ * Correspondence: grunwaldt@kit.edu; Tel.: +49-721-608-42120
}

Received: 1 August 2017; Accepted: 5 September 2017; Published: 18 September 2017

\begin{abstract}
The methanation of $\mathrm{CO}_{2}$ within the power-to-gas concept was investigated under fluctuating reaction conditions to gather detailed insight into the structural dynamics of the catalyst. A $10 \mathrm{wt} \% \mathrm{Ni} / \mathrm{Al}_{2} \mathrm{O}_{3}$ catalyst with uniform $3.7 \mathrm{~nm}$ metal particles and a dispersion of $21 \%$ suitable to investigate structural changes also in a surface-sensitive way was prepared and characterized in detail. Operando quick-scanning X-ray absorption spectroscopy (XAS/QEXAFS) studies were performed to analyze the influence of $30 \mathrm{~s}$ and $300 \mathrm{~s} \mathrm{H}_{2}$ interruptions during the methanation of $\mathrm{CO}_{2}$ in the presence of $\mathrm{O}_{2}$ impurities (technical $\mathrm{CO}_{2}$ ). These conditions represent the fluctuating supply of $\mathrm{H}_{2}$ from renewable energies for the decentralized methanation. Short-term $\mathrm{H}_{2}$ interruptions led to oxidation of the most reactive low-coordinated metallic Ni sites, which could not be re-reduced fully during the subsequent methanation cycle and accordingly caused deactivation. Detailed evaluation of the extended X-ray absorption fine structure (EXAFS) spectra showed surface oxidation/reduction processes, whereas the core of the Ni particles remained reduced. The 300-s $\mathrm{H}_{2}$ interruptions resulted in bulk oxidation already after the first cycle and a more pronounced deactivation. These results clearly show the importance and opportunities of investigating the structural dynamics of catalysts to identify their mechanism, especially in power-to-chemicals processes using renewable $\mathrm{H}_{2}$.
\end{abstract}

Keywords: $\mathrm{CO}_{2}$ methanation; dynamic reaction conditions; operando XAS; quick-EXAFS; surface oxidation-reduction; $\mathrm{H}_{2}$ dropout

\section{Introduction}

The power-to-chemicals concept is an important strategy for future renewable energy systems based on chemical energy storage. The splitting of water to produce $\mathrm{H}_{2}$ and the catalytic conversion of $\mathrm{CO}_{2}$ to methane, alkanes, methanol or higher alcohols are the main steps to generate a chemical energy carrier [1-4]. Both steps need to withstand fluctuations in supplied electricity from wind and solar plants, which occur temporarily and fluctuate on a time scale of seconds to days. When using 
a small or even no $\mathrm{H}_{2}$ reservoir, these fluctuations are transferred to the catalytic reactor imposing a varying supply of $\mathrm{H}_{2}$ used to hydrogenate $\mathrm{CO}_{2}[5-8]$.

Methane (synthetic or substitute natural gas) as one possible chemical energy carrier can be distributed easily and unlimitedly in the existing natural gas grid. The dynamics in the methanation originating from fast load changes of the $\mathrm{H}_{2}$ supply are a key challenge [5] and are therefore the subject of present research. The catalytic methanation of $\mathrm{CO}_{2}$ is well-known, and numerous articles can be found in the literature reporting $\mathrm{CO}_{2}$ conversion and $\mathrm{CH}_{4}$ selectivity under optimized and steady state conditions $[9,10]$. Ni-based catalysts generally achieve good activity. In addition, due to the low cost and high activity, Ni catalysts have emerged as the most commonly-used methanation catalysts [11-18], since more active Ru catalysts $[19,20]$ suffer from the high price of the noble metal. The most relevant catalyst support material in industrial methanation reactions is reported to be $\gamma-\mathrm{Al}_{2} \mathrm{O}_{3}$ with a high surface area $[19,21,22]$.

Methanation under transient reaction conditions has been performed to gain a better understanding of the mechanism, investigating the adsorbed species while switching between different gas mixtures [23,24]. Simulations of dynamic methanation reactors have been conducted to gain kinetic data and to address problems such as overheating during the transient process $[25,26]$. Other systems that have been studied under transient reaction conditions are, e.g., the Fischer-Tropsch reaction, where the influence of unsteady state conditions on the process itself was investigated $[7,8,27]$. Various spectroscopic, microscopic and diffraction techniques applied under reaction conditions revealed different structural changes of catalysts used in processes operated under changing reaction atmospheres [28-33].

Previous studies have shown that during the dynamic methanation of technical $\mathrm{CO}_{2}$, a fast partial oxidation of Ni-based catalysts occurred in a less reducing atmosphere after a $\mathrm{H}_{2}$ dropout, which caused a deactivation in the following methanation sequence due to the presence of inactive $\mathrm{NiO}$ on the metallic catalyst [22]. Further deactivation occurred over cycles, but the initial catalytic activity was recovered using reactivation in $\mathrm{H}_{2}$ at elevated temperatures [34]. In general, interruptions in the $\mathrm{H}_{2}$ feed must be prevented in methanation processes using $\mathrm{CO}_{2}$ with traces of oxygen (technical $\mathrm{CO}_{2}$ ), since otherwise reactivation is required to retrieve high catalytic performance. Hence, methanation reactors have to be kept under a reducing atmosphere during stand-by operation [6]. Within this study, we provide a more detailed insight into the kinetics and mechanisms of the redox processes in methanation applications using $\mathrm{CO}_{2}$ directly produced from biogas plants or exhaust gas from power plants containing traces of oxygen $[35,36]$. Based on these considerations, highly time-resolved operando XAS (quick-EXAFS (QEXAFS)) experiments were performed to evaluate the sensitivity of the catalyst towards deactivation. Furthermore, experiments including fast switches of the gas atmospheres were performed to obtain insights into blocking of active sites under fast load changes and thus mechanistic aspects in the methanation of $\mathrm{CO}_{2}$.

\section{Results and Discussion}

\subsection{Preparation, Characterization and Catalytic Performance}

A catalyst featuring uniform and rather small Ni particles was essential to determine the structural changes both of the surface and the bulk of the Ni particles during dynamically operated methanation. The homogeneous deposition-precipitation method was chosen to obtain a $\mathrm{Ni} / \mathrm{Al}_{2} \mathrm{O}_{3}$ catalyst with these properties. Elemental analysis using optical emission spectroscopy with an inductively-coupled plasma (ICP-OES) confirmed a catalyst loading of $10 \mathrm{wt} \% \mathrm{Ni} / \mathrm{Al}_{2} \mathrm{O}_{3}$. The specific surface area of the catalyst was $200 \mathrm{~m}^{2} / \mathrm{g}$, and the mean pore diameter was $11 \mathrm{~nm}$. X-ray diffraction (XRD) was not suitable to analyze the catalyst, since the $\mathrm{Ni}$ and $\mathrm{NiO}$ reflections were either superimposed by the signals of the support, the particles were too small to create reflections or the phases were X-ray amorphous, respectively (cf. the Supplementary Materials, XRD patterns in Figure S1). 
As shown in Figure 1, electron microscopy revealed a homogeneous dispersion of the particles on the support resulting in small Ni particles with a diameter of $3.7 \pm 1.2 \mathrm{~nm}$, a narrow size distribution and a Ni dispersion of $21 \%$. These values are comparable with those reported in the literature for supported Ni catalysts that were prepared using the same preparation technique $[37,38]$.

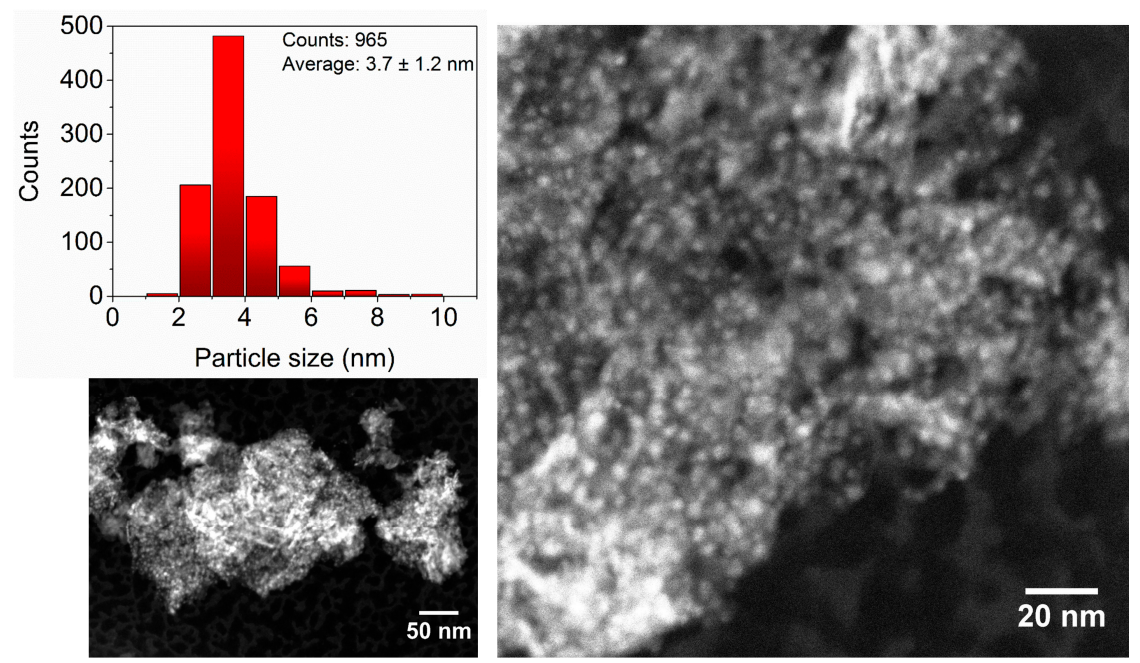

Figure 1. Scanning transmission electron microscopy (STEM) images and particle size distribution (top left) of the $10 \mathrm{wt} \% \mathrm{Ni} / \mathrm{Al}_{2} \mathrm{O}_{3}$ catalyst prepared by homogeneous deposition-precipitation.

As an additional characterization tool, temperature programmed reduction (TPR) experiments were used, which showed $\mathrm{H}_{2}$ consumption in a small temperature range (peak maximum at $565{ }^{\circ} \mathrm{C}$, cf. Figure S2), confirming the uniform particle size and the absence of agglomerates or larger particles. Furthermore, the Ni particles were reduced at lower temperature compared to other $\mathrm{Ni} / \mathrm{Al}_{2} \mathrm{O}_{3}$ catalysts reported in the literature (peak maxima between 680 and $800{ }^{\circ} \mathrm{C}$ [39-41]), which suggests a weaker metal-support interaction in the catalyst prepared in this study due to the synthesis method.

The catalyst was applied in the methanation of $\mathrm{CO}_{2}$ and showed high conversion and selectivity with $\mathrm{CO}$ being the only by-product (Figure 2). As the carbon balance was almost closed and therefore the calculation of the conversion according to Equations (1) and (2) (cf. Section 3) was similar, the formation of other products in significant amounts can be excluded. In Figure 2, the values obtained from Equation (1) are shown.

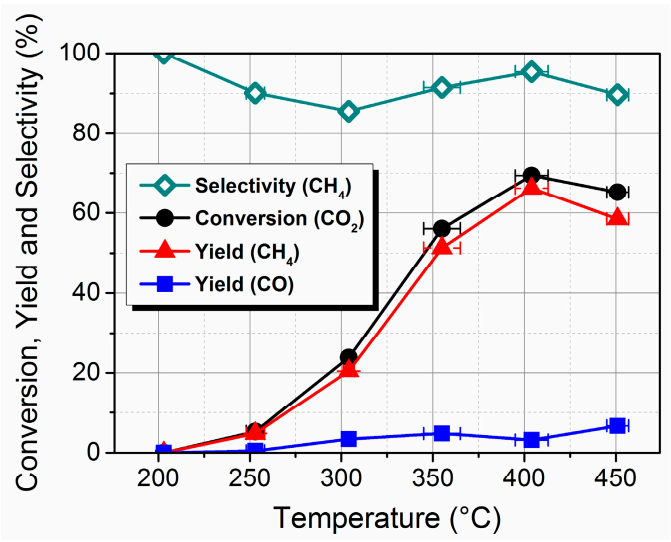

Figure 2. Conversion of $\mathrm{CO}_{2}$ (black), yield of $\mathrm{CH}_{4}$ (red) and yield of $\mathrm{CO}$ (blue), as well as selectivity of $\mathrm{CH}_{4}$ (green) for the $10 \mathrm{wt} \% \mathrm{Ni} / \mathrm{Al}_{2} \mathrm{O}_{3}$ catalyst; conditions: stainless steel tubular fixed-bed reactor, $150 \mathrm{mg}$ catalyst, $\mathrm{H}_{2} / \mathrm{CO}_{2}=4,75 \% \mathrm{~N}_{2}, \mathrm{p}=1 \mathrm{~atm}, \mathrm{~T}=200-450{ }^{\circ} \mathrm{C}$, gas hourly space velocity (GHSV) of $26,700 \mathrm{~h}^{-1}$ and weight hourly space velocity (WHSV) of $12,000 \mathrm{~mL}_{\mathrm{CO}_{2}} /\left(\mathrm{g}_{\text {cat }} \cdot \mathrm{h}\right)$. 
The formation of $\mathrm{CH}_{4}$ started between 200 and $250^{\circ} \mathrm{C}$, and the conversion of $\mathrm{CO}_{2}$ increased with rising temperature, reaching the highest value of $69 \%$ at $400{ }^{\circ} \mathrm{C}$ at a maximum selectivity towards $\mathrm{CH}_{4}$ of $95 \%$. At $450{ }^{\circ} \mathrm{C}$, the conversion of $\mathrm{CO}_{2}$ declined, and the selectivity shifted more toward $\mathrm{CO}$ due to the endothermic back reaction and the reverse water-gas shift reaction, which are preferred at higher temperatures [42]. The results are comparable with reports in the literature using $\mathrm{Ni} / \mathrm{Al}_{2} \mathrm{O}_{3}$ catalysts treated under related reaction conditions $[19,43]$. The turnover frequency (TOF) at $250{ }^{\circ} \mathrm{C}$ was calculated as $0.02 \mathrm{~s}^{-1}$ or as $0.08 \mathrm{~s}^{-1}$ at $300{ }^{\circ} \mathrm{C}$. The TOFs for $\mathrm{Ni} / \mathrm{Al}_{2} \mathrm{O}_{3}$ methanation catalysts reported in the literature cover a broad range between $0.69 \mathrm{~s}^{-1}$ [11], $0.10 \mathrm{~s}^{-1}$ [18], 0.041-0.097 $\mathrm{s}^{-1}$ [12] and $0.5 \times 10^{-3}-2.4 \times 10^{-3} \mathrm{~s}^{-1}$ [17]. The achieved TOFs correspond to typical dimensions; however, it is difficult to compare the results due to the diverse reaction conditions applied in these studies. In conclusion, the catalyst used in this study can be regarded as a representative methanation catalyst, which is well suited for our experiments to evaluate the effects of fluctuating reaction conditions on the structure of the active component and their impact on the catalyst activity.

\subsection{Operando QEXAFS Studies under Transient Reaction Conditions}

Operando X-ray absorption spectroscopic (XAS) studies were performed to gather information on the oxidation state and the atomic structure of nickel during methanation conditions and, especially, during short periods of hydrogen dropout. In previous studies, we observed a significant oxidation of nickel particles, when $\mathrm{H}_{2}$ was withdrawn from the reaction feed, leading to a lower catalytic activity during the subsequent methanation cycle [22,34]. In those studies, however, the hydrogen feed was interrupted for long periods of time (approximately $1 \mathrm{~h}$ ) since conventional XAS methods were used, which require relatively long acquisition times per spectrum (approximately $5 \mathrm{~min}$ ). Therefore, in the present study, we applied the quick-scanning EXAFS (QEXAFS) technique [44-46] to obtain data even in the sub-second regime for studying the impact of short hydrogen dropouts (30-300 s).

The methanation of technical $\mathrm{CO}_{2}$ containing traces of oxygen and the simulation of the $\mathrm{H}_{2}$ dropouts were performed at $400{ }^{\circ} \mathrm{C}$ (highest conversion and selectivity, compare Figure 2) and the same weight hourly space velocity (WHSV) applied in the activity measurements. Before each experiment, the catalyst was reduced in $50 \% \mathrm{H}_{2} / \mathrm{He}$ at $500{ }^{\circ} \mathrm{C}$. To simulate a short dropout of $\mathrm{H}_{2}$, caused for example by fluctuations in the hydrogen feed or by an unexpected change of the operation mode, hydrogen was switched on and off. The results of the experiment are presented in Figure 3.

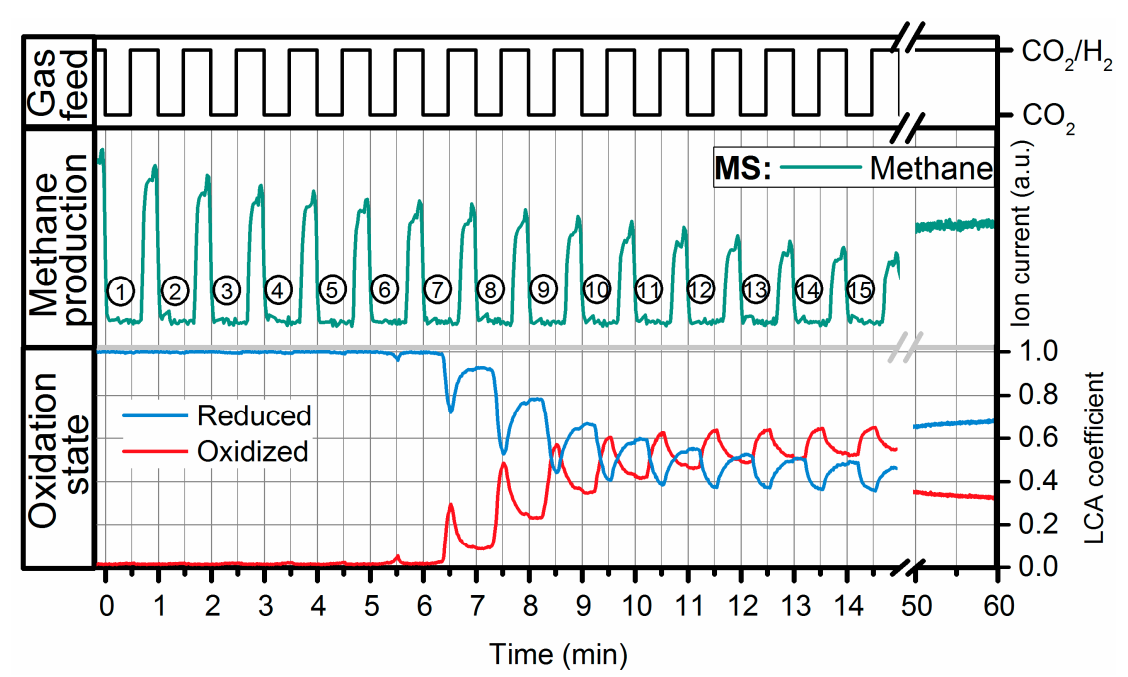

Figure 3. Methanation of $\mathrm{CO}_{2}$ during dynamic operation, switching every 30 s between methanation conditions $\left(\mathrm{H}_{2} / \mathrm{CO}_{2}=4\right)$ and $\mathrm{CO}_{2}$ at constant WHSV of $12,000 \mathrm{~mL}_{\mathrm{CO}_{2}} /\left(\mathrm{g}_{\text {cat }} \cdot \mathrm{h}\right)$ and $\mathrm{GHSV}$ of $71,700 \mathrm{~h}^{-1}$. The figure shows the valve signal in the upper part (black), the $\mathrm{CH}_{4}$ signal of the mass spectrometer $(m / z 15)$ in the middle part (green) and the fraction of reduced (blue) and oxidized (red) Ni from LCA of the X-ray absorption near edge structure (XANES) spectra. The numbers in circles count the $\mathrm{H}_{2}$ dropouts. 
First, the fully-reduced catalyst was exposed to methanation conditions $\left(\mathrm{H}_{2} / \mathrm{CO}_{2}=4 ; 75 \% \mathrm{He}\right)$. After several minutes of operation and a stable mass spectrometer (MS) signal of methane, the catalyst was subjected to a period of fluctuating $\mathrm{H}_{2}$ feed for $15 \mathrm{~min}$. During this modulation, the feed was switched every $30 \mathrm{~s}$ between $5 \% \mathrm{CO}_{2} / \mathrm{He}$ and methanation conditions $\left(\mathrm{H}_{2} / \mathrm{CO}_{2}=4\right)$. Finally, the catalyst was again exposed to steady state methanation conditions. The applied feed composition expressed as the signal of the valve position is depicted in the upper part of Figure 3. The product gas was monitored during the entire experiment; all analyzed components are shown in the Supplementary Materials (Figure S14). The methane production was monitored by mass spectrometry $(m / z 15)$, and the resulting signal is presented in the middle part of Figure 3. Throughout the experiment, $\mathrm{X}$-ray absorption spectra were recorded with an acquisition rate of 44 spectra/s. The X-ray absorption near edge structure (XANES, exemplary sequence, see Figure 4) spectra were evaluated with linear combination analysis (LCA, details, cf. the Supplementary Materials) to monitor the Ni oxidation state during transient conditions. The results are plotted in the bottom part of Figure 3.

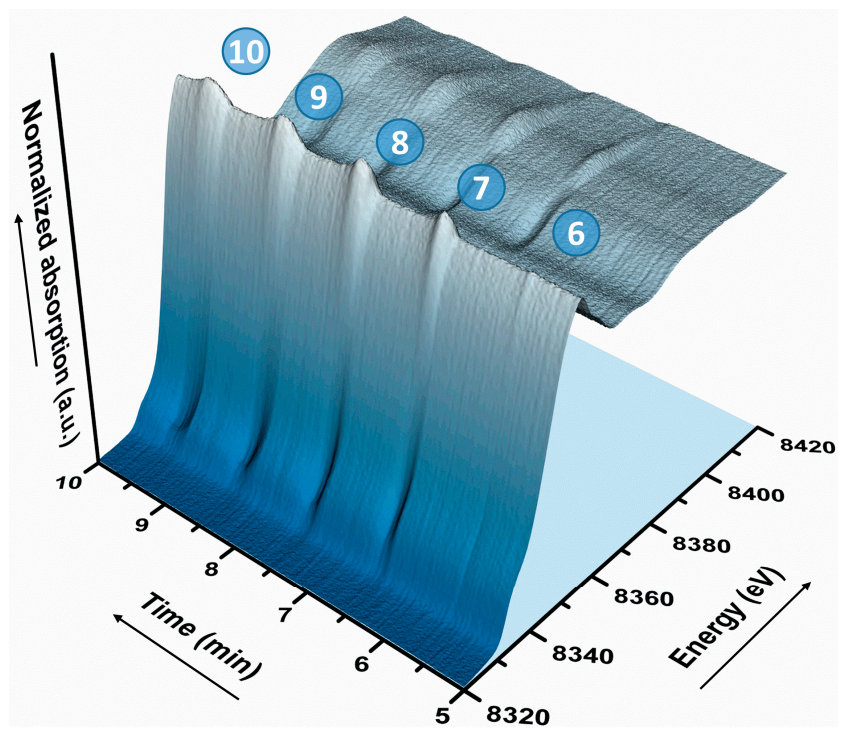

Figure 4. Section of the X-ray absorption near edge structure (XANES) spectra during the 30-s $\mathrm{H}_{2}$ dropout modulation (dropout Nos. 6-10 according to Figure 3).

The Ni particles were reduced during the methanation of $\mathrm{CO}_{2}\left(\mathrm{H}_{2} / \mathrm{CO}_{2}=4\right)$, and an intense signal assigned to methane was observed in the mass spectrometer data. Short $\mathrm{H}_{2}$ cut-offs, however, strongly affected the catalyst and its activity. As $\mathrm{H}_{2}$ was switched back on the stream after a 30-s period of a less reducing atmosphere without $\mathrm{H}_{2}(0-0.5 \mathrm{~min})$, a slightly decreased methane signal was observed. The methane production decreased further with each $\mathrm{H}_{2}$ dropout. However, no significant change of the Ni oxidation state was monitored during the first $5 \mathrm{~min}$ of the experiment. During the sixth $\mathrm{H}_{2}$ free period (after $5.5 \mathrm{~min}$ ), a first slight oxidation of $\mathrm{Ni}$ to a fraction of $6 \%$ was observed, which was still accounted to be negligible. Fast and significant oxidation of Ni during the seventh $\mathrm{H}_{2}$ dropout (at 6-6.5 $\mathrm{min}$ ) was observed by XAS, indicated by the increasing intensity of the white line. As discussed later in this paper, the oxidation of $\mathrm{Ni}$ in the absence of $\mathrm{H}_{2}$ was caused by the traces of oxygen present in the technical $\mathrm{CO}_{2}$. The oxidation stopped at $29 \%$ oxidized $\mathrm{Ni}$ according to LCA when $\mathrm{H}_{2}$ was switched back to the feed at $6.5 \mathrm{~min}$. Even though the catalyst was exposed to the $\mathrm{H}_{2}$ containing atmosphere for $30 \mathrm{~s}$ (at 6.5-7 min), it did not regain its initial state, and $9 \%$ of the $\mathrm{Ni}$ atoms remained oxidized. The percentage of oxidized Ni species increased steadily during the subsequent modulation until the 12 th $\mathrm{H}_{2}$ dropout, during which approximately $65 \%$ of the $\mathrm{Ni}$ atoms were oxidized. In the following oxidation and reduction events (between 11 and $15 \mathrm{~min}$ ), a marginal but no significant increase in the percentage of oxidized Ni was observed, and the fraction of 
oxidized Ni remained at a constant level altering between $65 \%$ and $50 \%$ over cycles. Nevertheless, the deactivation of the catalyst continued steadily as shown by the decreasing MS signal of methane.

During the ensuing $10 \mathrm{~min}$ of modulation, the changes of the catalyst (altering oxidation/reduction and continuous deactivation) followed the same trend and are therefore not shown here (full range experiment, see Figure S5). After the period of fluctuating operation ( $25 \mathrm{~min}$ in total), a sequence of steady state methanation was performed during which the oxidation state of the catalyst and structure was further monitored. During a 30-min measuring period, significant reduction of Ni was observed over time. This process, however, was very slow, and even after $30 \mathrm{~min}$ (final $5 \mathrm{~min}$ of this sequence shown in Figure 3), the initial oxidation state was not regained and 30\% still remained oxidized. Consequently, the catalyst was less active and showed a similar methane production and oxidized fraction as observed after the ninth $\mathrm{H}_{2}$ dropout. This supports a correlation between the oxidized fraction of $\mathrm{Ni}$ and the formation of methane [22]. Obviously, the temperature of $400{ }^{\circ} \mathrm{C}$ was too low to reduce Ni completely, which would have necessitated a re-activation of the catalyst at elevated temperatures [34].

The active catalyst state was obviously very sensitive towards oxidation, and already, a short exposure to a less reducing atmosphere was sufficient to initiate oxidation of $\mathrm{Ni}$ resulting in lower activity. Therefore, the full extended X-ray absorption fine structure (EXAFS) spectra were further evaluated to extract information on the local structural changes of the Ni catalyst during fluctuating conditions. In Figure 5a, Fourier-transformed (FT) EXAFS spectra are presented along with best fitting parameters obtained by fitting the first two coordination shells (Figure 5b). The EXAFS evaluation of the cycles 6-8 is shown in Figure 6; the structural parameters and the fully analyzed dataset are listed in Table 1; more details are shown in the Supplementary Materials.

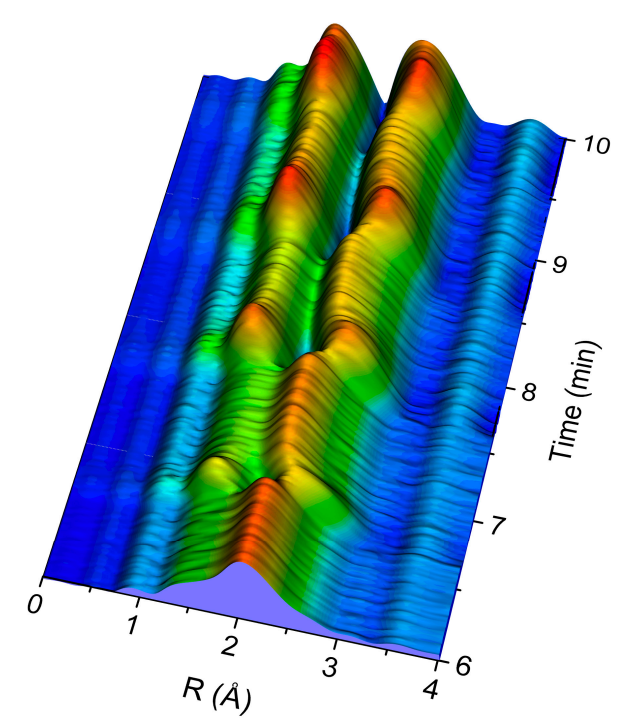

(a)

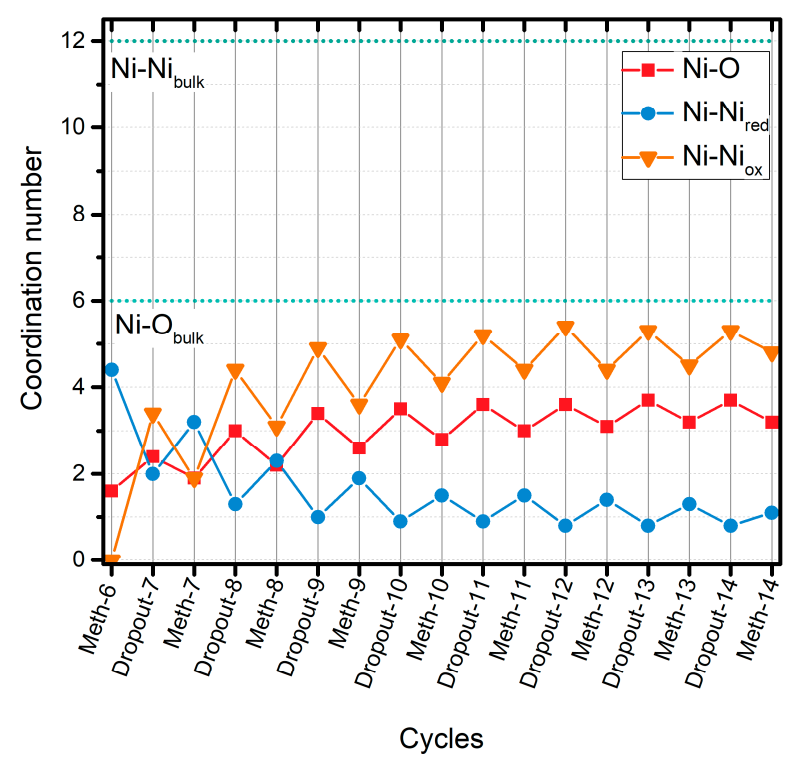

(b)

Figure 5. (a) Fourier-transformed extended X-ray absorption fine structure (FT EXAFS) data ( $k$ : 3-11 $\AA^{-1} ; k^{2}$-weighted, not phase corrected) during 30-s $\mathrm{H}_{2}$ dropouts (starting at the methanation sequence before the seventh $\mathrm{H}_{2}$ dropout (Meth-6)); (b) Results of the EXAFS fitting analysis during the 30-s modulation. The final spectra of each sequence (methanation sequences labeled as "Meth") were analyzed (details, cf. the Supplementary Materials). The coordination numbers $(\mathrm{N})$ of neighboring atoms are presented: $\mathrm{Ni}-\mathrm{O}$ and $\mathrm{Ni}-\mathrm{Ni}_{\mathrm{ox}}$ correspond to $\mathrm{O}$ and $\mathrm{Ni}$ coordination numbers, respectively, in oxidized nickel and $\mathrm{Ni}-\mathrm{Ni}_{\text {red }}$ to the coordination number of the first nickel shell in reduced nickel. 

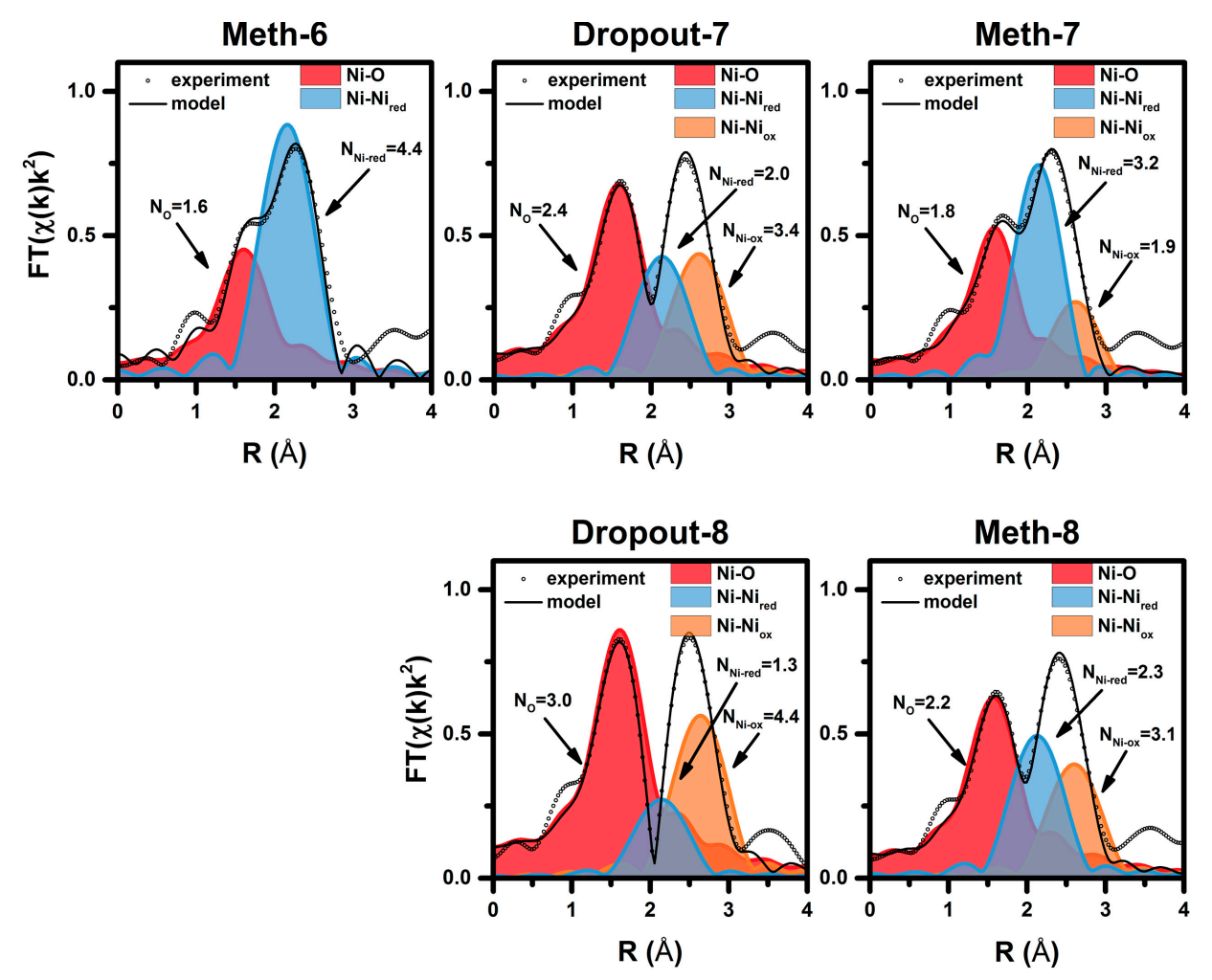

Figure 6. Experimental and simulated FT EXAFS data (magnitude, not phase shift corrected) of the Ni catalyst during 30-s modulation, in addition, the estimated Ni coordination numbers (Cycles 6-8), $k$-range 3-9 $\AA^{-1}$, $k$-weight $=2$ (for details, see the Supplementary Materials).

Table 1. Structural parameters of the local Ni atomic environment extracted from the best fitting EXAFS spectra shown in Figure 6. $k$ range $=3-9 \AA^{-1}, \mathrm{R}$ range $=1.2-3.2 \AA, \mathrm{N}^{\text {ind }}=6, \mathrm{~N}^{\mathrm{var}}=5$, $\mathrm{a}=$ fitted uncertainty 0.01 or lower, $\mathrm{f}=$ fixed during fit, $\mathrm{N}=$ number of neighboring atoms, $\mathrm{R}=$ distance, $\sigma^{2}=$ mean square deviation of interatomic distance, $\mathrm{R}$ factor $=$ misfit between experimental data and theory (for details, see the Supplementary Materials).

\begin{tabular}{|c|c|c|c|c|c|c|}
\hline Cycle & Atom & $\mathbf{N}$ & $\mathrm{R}(\AA)^{\mathrm{a}}$ & $\sigma^{2} \cdot 10^{-3}\left(\AA^{2}\right)$ & $\mathrm{E}_{0}(\mathrm{eV})$ & R Factor (\%) \\
\hline \multirow{2}{*}{ Meth-6 } & $\mathrm{O}$ & $1.6 \pm 0.2$ & $2.03 \pm 0.2$ & $8.3^{f}$ & \multirow{2}{*}{$9.0 \pm 1.5$} & \multirow{2}{*}{0.27} \\
\hline & $\mathrm{Ni}$ & $4.4 \pm 0.3$ & $2.49 \pm 0.1$ & $11.8^{\mathrm{f}}$ & & \\
\hline \multirow{3}{*}{ Dropout-7 } & $\mathrm{O}$ & $2.4 \pm 0.2$ & $2.02 \pm 0.03$ & $8.3^{f}$ & \multirow{3}{*}{$7.6 \pm 2.9$} & \multirow{3}{*}{0.25} \\
\hline & $\mathrm{Ni}$ & $2.0 \pm 0.6$ & $2.48 \pm 0.02$ & $11.4^{\mathrm{f}}$ & & \\
\hline & $\mathrm{Ni}$ & $3.4 \pm 0.9$ & $2.96 \pm 0.03$ & $11.8^{\mathrm{f}}$ & & \\
\hline \multirow{3}{*}{ Meth-7 } & $\mathrm{O}$ & $1.8 \pm 0.2$ & $2.01 \pm 0.2$ & $8.3^{f}$ & \multirow{3}{*}{$6.4 \pm 2.2$} & \multirow{3}{*}{0.23} \\
\hline & $\mathrm{Ni}$ & $3.2 \pm 0.4$ & $2.48 \pm 0.1$ & $11.4^{\mathrm{f}}$ & & \\
\hline & $\mathrm{Ni}$ & $1.9 \pm 0.6$ & $2.95 \pm 0.3$ & $11.8^{\mathrm{f}}$ & & \\
\hline \multirow{3}{*}{ Dropout-8 } & $\mathrm{O}$ & $3.0 \pm 0.2$ & $2.04 \pm 0.02$ & $8.3^{f}$ & \multirow{3}{*}{$8.9 \pm 2.1$} & \multirow{3}{*}{0.14} \\
\hline & $\mathrm{Ni}$ & $1.3 \pm 0.6$ & $2.48 \pm 0.03$ & $11.4^{\mathrm{f}}$ & & \\
\hline & $\mathrm{Ni}$ & $4.4 \pm 0.7$ & $2.97 \pm 0.03$ & $11.8^{\mathrm{f}}$ & & \\
\hline \multirow{3}{*}{ Meth-8 } & $\mathrm{O}$ & $2.2 \pm 0.2$ & $2.02 \pm 0.03$ & $8.3^{f}$ & \multirow{3}{*}{$6.8 \pm 2.9$} & \multirow{3}{*}{0.23} \\
\hline & $\mathrm{Ni}$ & $2.3 \pm 0.6$ & $2.48 \pm 0.01$ & $11.4^{\mathrm{f}}$ & & \\
\hline & $\mathrm{Ni}$ & $3.1 \pm 0.9$ & $2.96 \pm 0.03$ & $11.8^{f}$ & & \\
\hline
\end{tabular}

For the first six cycles, no significant changes in the EXAFS spectra were observed. The spectra were dominated by a feature at about $2 \AA$, predominantly originating from Ni neighbors in reduced Ni. The evaluated interatomic distance of $2.49 \AA$ was similar to the one in metallic Ni. The O contribution 
determined in the reduced state may originate from the oxide support or incomplete reduction of the $\mathrm{Ni}$ particles. Including a $\mathrm{Ni}^{-\mathrm{Ni}_{\mathrm{ox}}}$ (the $\mathrm{Ni}-\mathrm{Ni}$ backscattering contribution in nickel oxide) bond pair led to a worse fit and was therefore not considered in Meth-6. During the seventh $\mathrm{H}_{2}$ dropout, when significant oxidation was observed for the first time (cf. LCA in Figure 3), changes in the FT EXAFS data were observed, indicating substantial changes in the structure of the Ni nanoparticles. During oxidation, the feature at $2 \AA$ in the EXAFS spectra resulting from reduced Ni-Ni coordination disappeared quickly and was replaced by two peaks related to the $\mathrm{O}$ and Ni neighbors in a NiO-like structure. The evaluation of the final EXAFS spectra of each sequence (methanation atmosphere or less reducing atmosphere, respectively) facilitated monitoring the evolution of the respective coordination shells during fluctuating operation. The respective coordination numbers are therefore plotted in Figure $5 b$ for this purpose. The data revealed the transformation from a reduced Ni particle to a partially-oxidized Ni particle. Even though the Ni particles were very small, they did not get fully oxidized due to the short duration of $\mathrm{H}_{2}$ dropout indicating that a core of reduced $\mathrm{Ni}$ remained (coordination number $\mathrm{N}_{\mathrm{Ni}-\mathrm{Ni} \text {,red }}>1$ ). After the 12th dropout, predominantly a reversible oxidation and reduction was observed, in accordance with the LCA discussed earlier, and the core of the particles remained reduced.

The following steady state methanation operation (full-range experiment, see Figure S5) slowly transformed the catalyst back into its reduced state. However, even after $30 \mathrm{~min}$ in the methanation atmosphere, still, a significant fraction of nickel remained oxidized, also shown by the coordination numbers $\left(\mathrm{N}_{\mathrm{Ni}-\mathrm{O}}=2.2, \mathrm{~N}_{\mathrm{Ni}-\mathrm{Ni} \text {,red }}=2.4, \mathrm{~N}_{\mathrm{Ni}-\mathrm{Ni}, \text { ox }}=3.0\right.$, cf. Table S3). During this methanation experiment, only slight sintering was observed by an increase in the coordination number of reduced Ni by 0.2 . This is within the accuracy of the evaluation; however, the Ni coordination number increased by 0.5 after repeating the whole experiment of 30-s modulation three times further (see Table S2). Note that the evaluated $\mathrm{Ni}$ coordination was not adjusted to the fraction of the particles in the $\mathrm{Ni} / \mathrm{NiO}$ mixture, and no conclusion on the correlation between coordination number and particle size was drawn.

The delayed start of the Ni oxidation as observed in Figure 3 was rationalized when the spatial conditions of the experiment were considered [32,47]. XAS spectra were recorded in the middle of the catalyst bed with a $200 \mu \mathrm{m}$-sized X-ray beam and correlated to the integral activity data. Catalyst oxidation therefore probably started at the reactor inlet and propagated through the catalyst bed. We speculate that the oxidation was caused by the $\mathrm{O}_{2}$ background present in the $\mathrm{CO}_{2}$ feed (cf. the estimation in the later part of the paper), which oxidized a small amount of $\mathrm{Ni}$ at the reactor inlet in the short 30-s period in a less reducing atmosphere and was thereby completely consumed. Significant oxidation by $\mathrm{CO}_{2}$ was ruled out, as $\mathrm{CO}_{2}$ was present in excess and should then also have oxidized $\mathrm{Ni}$ in the middle of the reactor already at the beginning of the experiment (cf. Figure 3; oxidation started at the sixth switch). Furthermore, an additional experiment in the total absence of $\mathrm{O}_{2}$ using short and thin stainless steel tubing and a $\mathrm{CO}_{2}(99.998 \%)$ bottle directly placed next to the mass flow controllers showed that no catalyst deactivation occurred during $60 \mathrm{~s} \mathrm{H}_{2}$ dropouts (see Figure S17). Catalyst deactivation occurred during 300-s cycles when 300 ppm and 500 ppm $\mathrm{O}_{2}$ were added to the gas mixture, which was more pronounced with increasing $\mathrm{O}_{2}$ content (Figure S18). Finally, the oxidation of $\mathrm{Ni}$ by $\mathrm{CO}_{2}$ is thermodynamically unfavorable $(\Delta \mathrm{G}>0)$. Estimations of the amount of $\mathrm{O}_{2}$ present in the spectroscopic experiment based on the formation of $\mathrm{NiO}$ showed that an amount of around 1000 ppm was sufficient for the oxidation (for details, cf. the discussion of Figure S7 in the Supplementary Materials). Reduction of the whole catalyst bed was not achieved within the following $30 \mathrm{~s}$ during methanation at $400{ }^{\circ} \mathrm{C}$. Therefore, the overall fraction of oxidized Ni increased during fluctuating operation, causing the steady decrease in catalytic activity. The methane production decreased continuously, even after $\mathrm{Ni}$ reached a stable oxidized fraction at the monitored position (after the 12th $\mathrm{H}_{2}$ dropout), since Ni oxidation kept propagating towards the end of the catalyst bed.

To provoke a faster oxidation through the catalyst bed and to investigate the oxidation and its kinetics in a longer cycle duration, the catalyst was exposed to $\mathrm{H}_{2}$ dropout events to an extended period of $300 \mathrm{~s}$ in a subsequent experiment using the same catalyst sample. In this experiment 
(Figure 7), oxidation was observed immediately during the first dropout event. However, there was a significant delay (approximately $80 \mathrm{~s}$; details, see Figure S7) between the switch of the gas atmospheres and the oxidation observed in the XANES spectra, due to the gradual oxidation of the Ni along the catalyst bed. Again, oxidation was found to be fast, resulting in $91 \%$ of $\mathrm{NiO}$ at the end of the 300 -s cycle. Switching to methanation conditions after $300 \mathrm{~s}$ led to a re-reduction of the Ni particles and methane formation. About $38 \%$ of oxidized nickel remained on the catalyst and changed the overall catalyst composition resulting in a decreased catalytic activity in the second methanation cycle. Reduction occurred approximately $20 \mathrm{~s}$ after the gas switch and, therefore, seemed to propagate faster than the oxidation due to the much higher concentration of the reducing agent in the feed. In the following $\mathrm{H}_{2}$ dropout cycles, the maximum oxidized fraction in the less reducing atmospheres remained at approximately $95 \%$. Therefore, a 300-s $\mathrm{H}_{2}$ dropout led to a (nearly) complete oxidation of the catalyst. A slowly-progressing reduction of the catalyst was observed during the 30-min period of steady state methanation at the end of the experiment, reaching a final value of a $48 \%$ reduced fraction.

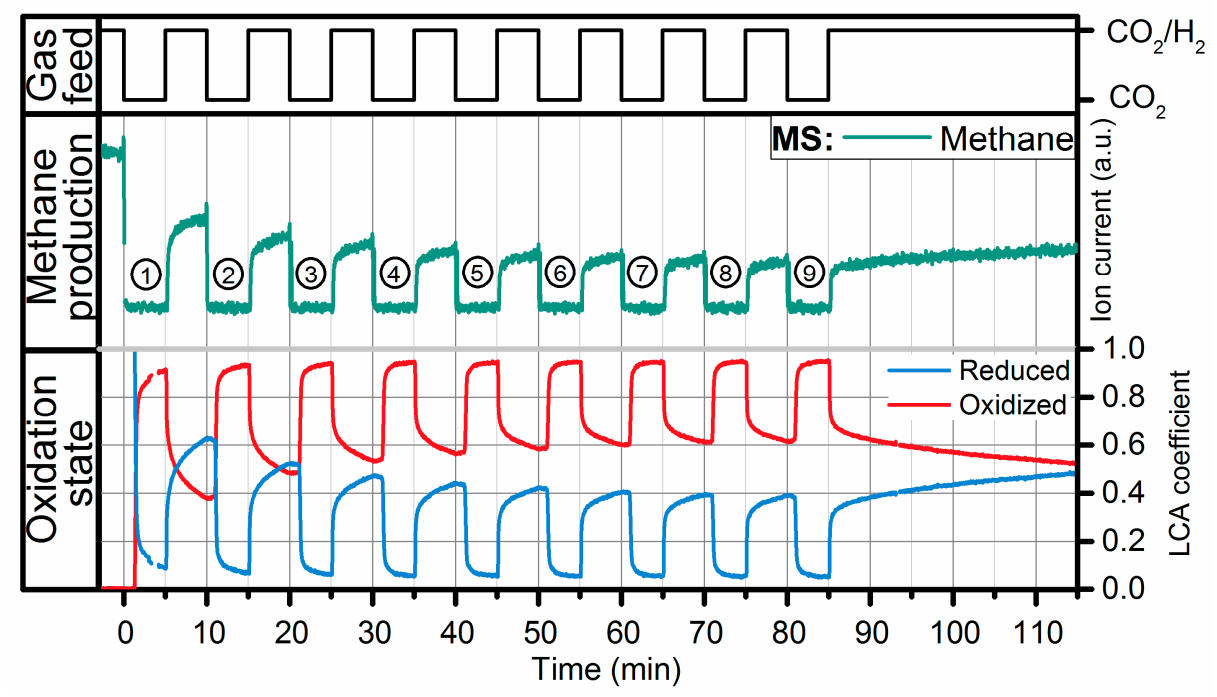

Figure 7. Methanation of $\mathrm{CO}_{2}$ during dynamic operation switching every $300 \mathrm{~s}$ between methanation conditions $\left(\mathrm{H}_{2} / \mathrm{CO}_{2}=4\right)$ and $\mathrm{CO}_{2}$ at constant WHSV of $12,000 \mathrm{~mL} \mathrm{CO}_{2} /\left(\mathrm{g}_{\text {cat }} \cdot \mathrm{h}\right)$ and $\mathrm{GHSV}$ of $71,700 \mathrm{~h}^{-1}$. The figure shows the valve signal in the upper part (black), the $\mathrm{CH}_{4}$ signal of the MS $(\mathrm{m} / z$ 15) in the middle part (green) and the fraction of reduced (blue) and oxidized (red) Ni from LCA of the XANES spectra. The numbers in cycles count the $\mathrm{H}_{2}$ dropouts.

Similar to the 30-s modulation, the estimated amount of $\mathrm{O}_{2}$ based on the formed $\mathrm{NiO}$ showed a value around 1000 ppm. Additional experiments with a quantified amount of $\mathrm{O}_{2}$ (Figure S18) showed a full Ni oxidation after a few 300-s $\mathrm{H}_{2}$ dropouts applying 500 ppm $\mathrm{O}_{2}$. Consequently, we assumed an $\mathrm{O}_{2}$ content between 500 and 1000 ppm present in the QEXAFS experiments. This small quantity is ideal to oxidize the most reactive sites and block in fact those Ni sites for methanation.

The FT EXAFS spectra collected during the 300-s modulation and the coordination numbers from the best fits of the EXAFS spectra are shown in Figure 8a,b, respectively. As already observed during the 30-s modulation, the FT EXAFS spectra in the reduced state were dominated by one signal at $2 \AA$, which was assigned to Ni-Ni coordination in reduced $\mathrm{Ni}$. Note that the $\mathrm{N}_{\mathrm{Ni}-\mathrm{Ni} \text {,red }}$ of 5.1 was slightly higher than the one determined from the EXAFS evaluation during the 30-s modulation $\left(\mathrm{N}_{\mathrm{Ni}-\mathrm{Ni} \text {,red }}=4.4\right)$. This can be explained by sintering of the Ni particles since the same sample was used for all experiments and three additional 30-s modulation experiments (not shown here) were performed before the 300-s modulation experiment (see Table S2). Applying the 300-s modulation, the maximum of the Ni-O path was already reached during the first $\mathrm{H}_{2}$ dropout. A bulk oxidation of the

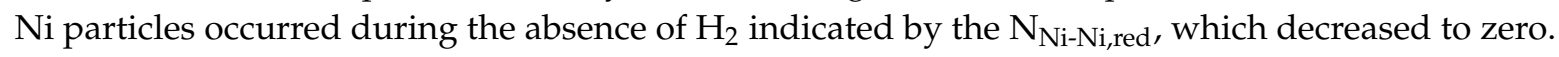


The oxidation state reached its steady state after the first cycle, while the amount of receded Ni during the methanation periods decreased until the fourth cycle.

Reduced Ni particles with a $\mathrm{N}_{\mathrm{Ni}-\mathrm{Ni} \text {, red }}$ of 5.1 were transformed into oxidized Ni particles with a $\mathrm{N}_{\mathrm{Ni}-\mathrm{Ni}, \mathrm{ox}}$ of 7.6. This can be either explained by incomplete reduction of the Ni particles contributing to the apparently lower coordination in reduced $\mathrm{Ni}$ and a higher coordination after oxidation. Another explanation for the difference in the coordination numbers can be a wetting effect of the flat reduced particles, increasing the contact with the oxidic support material, whereas the oxidized particles are more spherical with a higher average $\mathrm{Ni}-\mathrm{Ni}$ coordination [30].

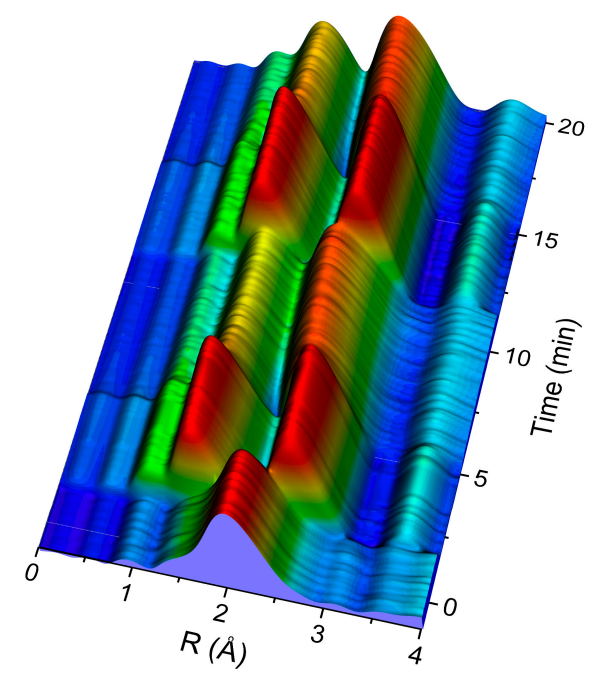

(a)

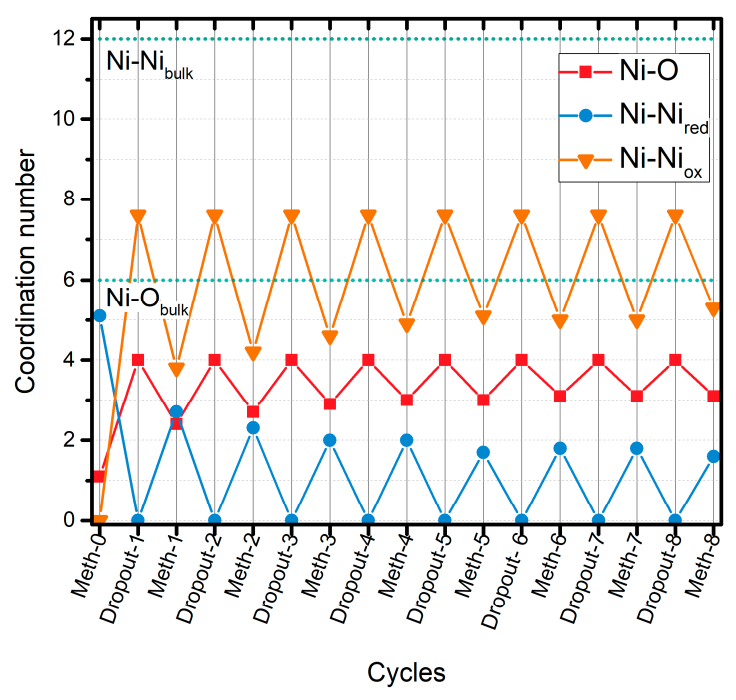

(b)

Figure 8. (a) FT EXAFS data ( $k$ : 3-11 $\AA^{-1} ; k^{2}$-weighted) during repeated 300-s $\mathrm{H}_{2}$ dropouts; (b) Results of the EXAFS fitting analysis during the 300-s modulation. The final spectra of each sequence were analyzed. The coordination numbers of neighboring atoms are presented: Ni-O and Ni-O-Ni correspond to $\mathrm{O}$ and $\mathrm{Ni}$ coordination numbers, respectively, in oxidized nickel and $\mathrm{Ni}-\mathrm{Ni}$ to the coordination number of the first nickel shell in reduced nickel.

The direct comparison of the MS signals of both modulation experiments (Figure S16) showed that the deactivation was more distinctive during 300-s switches, where a significantly lower $\mathrm{CH}_{4}$ signal was detected after the second cycle up until the end of the experiment. Furthermore, in the experiments with 30-s modulation, the catalyst was much more active during steady state methanation after the $\mathrm{H}_{2}$ dropout sequence. This observation clearly emphasized the correlation of the Ni oxidation state and the methanation activity. Comparing the results of the LCAs from both experiments, full oxidation was interrupted during the 30-s cycles due to the fast switching. During the 300-s modulation, the oxidation state reached a plateau indicating the complete oxidation process. Thus, the impact of the short cycles on the catalyst deactivation was less severe.

Figures 9 and 10 show schemes of the Ni particles during the dynamic methanation of $\mathrm{CO}_{2}$. Short-term $\mathrm{H}_{2}$ dropout (Figure 9) first led to an oxidation of the most reactive sites such as low coordinated $\mathrm{Ni}$ atoms located at step sites, defect sites or at the interface to the support material [48-52]. Particularly, the interface sites appear important for the methanation of $\mathrm{CO}_{2}$, since the key steps of the hydrogenation are speculated to take place at the interface of the metal particle and support $[53,54]$. Furthermore, step sites are more reactive in CO dissociation compared to plane facets [51,55]. $\mathrm{NiO}$ islands may form and grow to $\mathrm{NiO}$ structures of several layers [56,57]. Diffusion of oxygen into the bulk did not occur due to the short period of less reducing atmosphere. Full oxidation of the $\mathrm{Ni}$ particles was interrupted, and $\mathrm{NiO}$ planes were reduced partly in the methanation atmosphere. 


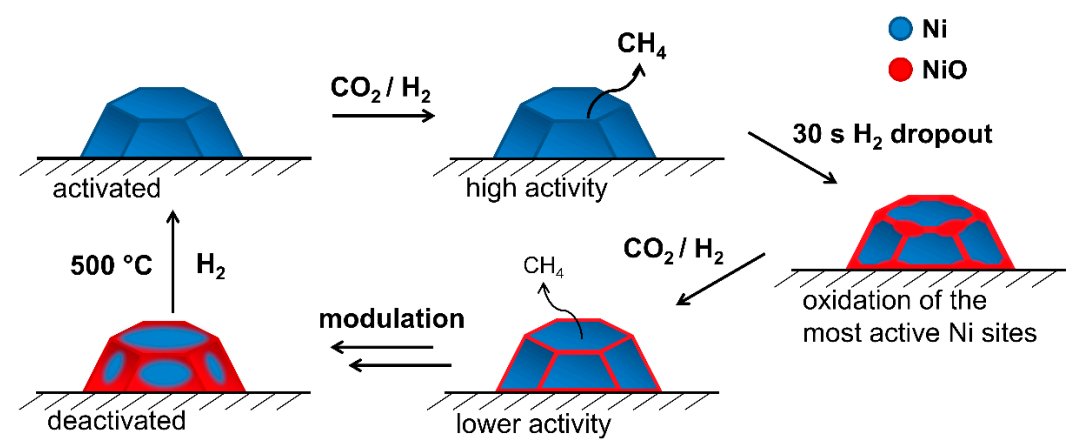

Figure 9. Scheme of the structural changes of supported Ni particles during the 30-s dropout modulations. Blue represents reduced $\mathrm{Ni}$, whereas red describes oxidized $\mathrm{Ni}$.

The highly active lower coordinated $\mathrm{Ni}$ sites remained oxidized under these reaction conditions due to their higher stability. Hence, the methanation of $\mathrm{CO}_{2}$ could only take place at the reduced $\mathrm{Ni}$ plane sites resulting in lower activity. This supports earlier studies in the literature $[48-50,58]$ that selective blockage of the low coordinated $\mathrm{Ni}$ edge or corner sites leads to differed or deteriorated catalytic properties. Similar structure sensitivity due to easier oxidation of low-coordinated sites was also observed during $\mathrm{CO}$ oxidation on Pt catalysts $[59,60]$. For example, oxidation of low coordinated $\mathrm{Pt}$ atoms located at edge and corner sites during CO oxidation was found by XAS resulting in an irreversible $\mathrm{CO}$ adsorption on $\mathrm{PtO}$ [61]. Cluster models show that metal particles of our size or dispersion contain $4 \%$ edge sites [62-65]. This value correlated with the remaining oxidized fraction $(10 \%)$ in the methanation sequence after the first oxidation during the seventh $\mathrm{H}_{2}$ dropout when additional sites at the interface, as well as corner and defect sites, would have been taken into account.

The schematic structural changes of Ni particles during 300-s modulations are illustrated in Figure 10. Compared to the short-time $\mathrm{H}_{2}$ dropouts, the longer $300 \mathrm{~s} \mathrm{H}_{2}$ dropouts resulted in a less reducing atmosphere enabling a complete oxidation of the Ni particles, which then suffer from insufficient re-reduction during the reducing methanation atmosphere.

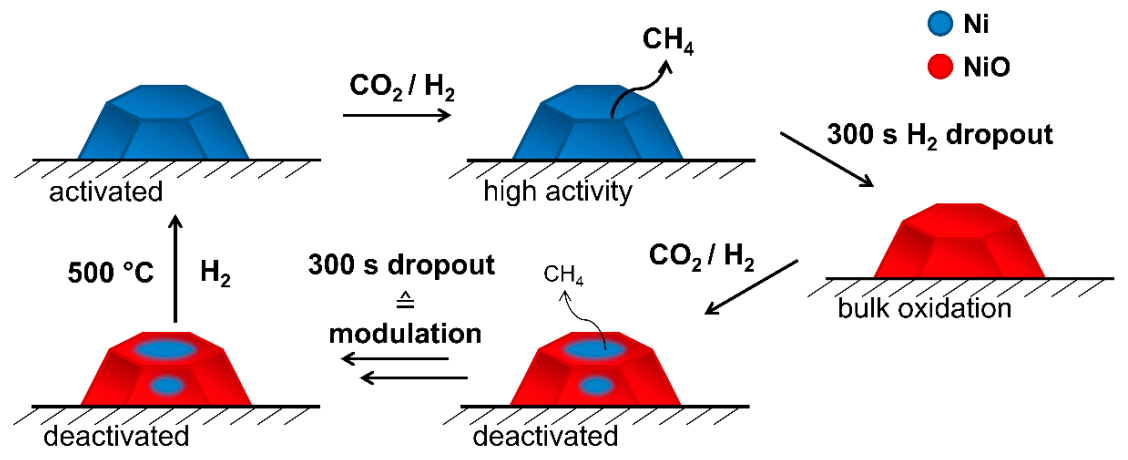

Figure 10. Scheme of the structure of the supported Ni particles exposed to $\mathrm{H}_{2}$ dropout modulations at a duration of $300 \mathrm{~s}$.

\section{Materials and Methods}

\subsection{Catalyst Preparation}

A $10 \mathrm{wt} \% \mathrm{Ni} / \mathrm{Al}_{2} \mathrm{O}_{3}$ catalyst was prepared via homogeneous deposition-precipitation using urea as the precipitating agent [66-68]. $\mathrm{Al}_{2} \mathrm{O}_{3}$ support (Alfa Aesar, Karlsruhe, Germany, 1/8 inch pellets, crushed to fine powder, calcined at $600{ }^{\circ} \mathrm{C}(5 \mathrm{~K} / \mathrm{min})$ for $\left.4 \mathrm{~h}\right)$ was suspended in a solution of $0.03 \mathrm{~mol} / \mathrm{L} \mathrm{Ni}\left(\mathrm{NO}_{3}\right)_{2} \cdot 6 \mathrm{H}_{2} \mathrm{O}$ (Merck, Darmstadt, Germany, $\geq 99 \%$ ) in water. Five equivalents of urea (Carl Roth, Karlsruhe, Germany, $\geq 99.6 \%$ ) were added to the mixture and stirred for $1 \mathrm{~h}$ at room 
temperature, where a $\mathrm{pH}$ value of 5 was observed. The suspension was then heated to $90{ }^{\circ} \mathrm{C}$ and stirred under reflux for $18 \mathrm{~h}$, cooled to room temperature and stirred for another hour, resulting in a final $\mathrm{pH}$ value of $7-8$. The solid was filtered, washed with deionized water, dried over night at $110^{\circ} \mathrm{C}$ and calcined for $4 \mathrm{~h}$ at $500{ }^{\circ} \mathrm{C}(5 \mathrm{~K} / \mathrm{min})$. Typically, $2 \mathrm{~g}$ of the catalyst were prepared in one batch containing $1.80 \mathrm{~g} \mathrm{Al}_{2} \mathrm{O}_{3}, 1.00 \mathrm{~g}$ Ni nitrate, $1.04 \mathrm{~g}$ urea and $115 \mathrm{~mL}$ water.

\subsection{Characterization}

The chemical composition was determined via optical emission spectroscopy with an inductively-coupled plasma (ICP-OES) using an Agilent (Waldbronn, Germany) 720/725 emission spectrometer. The specific surface area of the catalyst was determined using $\mathrm{N}_{2}$ physisorption at $-196^{\circ} \mathrm{C}$ according to the Brunauer-Emmet-Teller (BET) method via multipoint measurements using a BELSORP-mini II (MicrotracBEL, Osaka, Japan). X-ray diffraction (XRD) patterns were recorded in the range $2 \theta=20-80^{\circ}$ (step size $0.017^{\circ}, 0.51 \mathrm{~s}$ per scan step) using a rotating sample holder containing catalyst powder and a PANalytical (Almelo, The Netherlands) X'pert PRO diffractometer with Ni-filtered $\mathrm{Cu}-\mathrm{K} \alpha$ radiation (1.54060 $\mathrm{A}$ ). Scanning transmission electron microscopy (STEM) images were recorded using a FEI (Hillsboro, OR, USA) Titan 80-300 microscope operated at $300 \mathrm{kV}$ and a Fischione Model 3000 high-angle annular dark-field (HAADF-STEM) detector. The measurements were conducted using reduced catalyst powder dispersed on a gold grid covered with holey carbon film. The Ni particle size was determined with ImageJ software (1.48v, National Institutes of Health, Rockville, MD, USA, 2016) measuring the mean diameter of 965 marked particles using ellipsoid shapes. The Ni dispersion was calculated using the mean diameter of the Ni particles, the area occupied by a Ni surface atom and the volume occupied by a Ni atom in the bulk metal assuming spherical particles [69]. A Micromeritics (Aachen, Germany) AutoChem II 2920 chemisorption analyzer was used for temperature programmed reduction (TPR) experiments. One hundred milligrams of the catalyst sample $(100-200 \mu \mathrm{m})$ were placed in a U-shaped quartz tube and fixed with quartz wool plugs. First, the catalyst was heated to $500{ }^{\circ} \mathrm{C}(10 \mathrm{~K} / \mathrm{min})$ in $10 \% \mathrm{O}_{2}$ followed by the TPR between 40 and $900{ }^{\circ} \mathrm{C}(10 \mathrm{~K} / \mathrm{min})$ using $10 \% \mathrm{H}_{2}$. The $\mathrm{H}_{2}$ consumption was recorded using a thermal conductivity detector (TCD).

\subsection{Catalytic Performance}

The catalytic activity in the methanation of $\mathrm{CO}_{2}$ was tested in a continuous flow laboratory setup with a stainless steel reactor filled with a fixed-bed of $150 \mathrm{mg}$ catalyst sample (300-450 $\mu \mathrm{m}$, diluted in $\mathrm{SiC}$ ) operated in down-flow. The reactor was heated by a custom-made oven (HTM Reetz, Berlin, Germany), and the temperature was controlled using a thermocouple placed in front of the catalyst bed inside of the reactor and regulated by a Eurotherm 2416 PID controller. Gas dosing was adjusted using individual mass flow controllers (Bronkhorst, Ruurlo, The Netherlands). First, the catalyst was reduced in situ in $50 \% \mathrm{H}_{2} / \mathrm{N}_{2}(600 \mathrm{~mL} / \mathrm{min})$ at $500{ }^{\circ} \mathrm{C}(10 \mathrm{~K} / \mathrm{min})$ for $2 \mathrm{~h}$. Then, the reactor was cooled to $200{ }^{\circ} \mathrm{C}$, and the gas atmosphere was switched to $\mathrm{H}_{2} / \mathrm{CO}_{2}=4$ in $75 \% \mathrm{~N}_{2}(600 \mathrm{~mL} / \mathrm{min}$ total flow), resulting in a gas hourly space velocity (GHSV) of $26,700 \mathrm{~h}^{-1}$ (concerning total gas flow and catalyst volume) or a weight hourly space velocity (WHSV) of $12,000 \mathrm{~mL}_{\mathrm{CO}_{2}} /\left(\mathrm{g}_{\text {cat }} \cdot \mathrm{h}\right.$ ) (concerning gas flow of $\mathrm{CO}_{2}$ and catalyst mass), respectively. The methanation reaction was performed between 200 and $450{ }^{\circ} \mathrm{C}$ in $50^{\circ} \mathrm{C}$ steps to determine the optimum reaction conditions. Reactant and product gas compositions were analyzed by a Thermo Scientific (Waltham, MA, USA) C2V-200 micro gas chromatograph (microGC) equipped with a molecular sieve (5 $\mathrm{A}$ ) and a QS-BOND column and a thermal conductivity detector (TCD). Conversion, yield and selectivity were calculated as follows:

$$
\text { Conversion: } \mathrm{X}\left(\mathrm{CO}_{2}\right)=\left(1-\frac{\mathrm{CO}_{2, \text { out }}}{\mathrm{CO}_{2, \text { out }}+\mathrm{CH}_{4, \text { out }}+\mathrm{CO}_{\text {out }}}\right) \times 100 \%
$$

or including $\mathrm{N}_{2}$ as the internal standard:Conversion: 


$$
\begin{gathered}
\text { Conversion: } \mathrm{X}^{\prime}\left(\mathrm{CO}_{2}\right)=\left(1-\frac{\mathrm{CO}_{2, \text { out }} \times \mathrm{N}_{2, \text { in }}}{\mathrm{N}_{2, \text { out }} \times \mathrm{CO}_{2, \text { in }}}\right) \times 100 \% \\
\text { Yield: } \mathrm{Y}\left(\mathrm{CH}_{4} \text { or } \mathrm{CO}\right)=\frac{\mathrm{CH}_{4, \text { out }} \text { or } \mathrm{CO}_{\text {out }}}{\mathrm{CO}_{2, \text { out }}+\mathrm{CH}_{4, \text { out }}+\mathrm{CO}_{\text {out }}} \times 100 \% \\
\text { Selectivity: } \mathrm{S}\left(\mathrm{CH}_{4}\right)=\frac{Y\left(\mathrm{CH}_{4}\right)}{\mathrm{X}\left(\mathrm{CO}_{2}\right)} \times 100 \%
\end{gathered}
$$

The turnover frequency (TOF) was calculated as moles of $\mathrm{CH}_{4}$ produced per moles of Ni surface atoms per second using the inlet flow of $\mathrm{CO}_{2}$, the molar gas volume $V(m)$ and the catalyst mass:

$$
\mathrm{TOF}=\frac{\dot{V}\left(\mathrm{CO}_{2}, \text { in }\right) \times Y\left(\mathrm{CH}_{4}\right)}{V(m) \times N(\mathrm{Ni}, \text { surf }) \times m(\text { cat })}
$$

The number of $N i$ surface atoms per gram catalyst $N(N i$, surf $)$ was determined using the dispersion from TEM analysis [69].

\subsection{Operando XAS Experiments}

Quick-scanning X-ray absorption spectroscopy (QEXAFS) [70,71] was performed at the SuperXAS beamline at the Swiss Light Source (SLS) synchrotron facility (Paul Scherrer Institute, Villigen, Switzerland), which operates in top-up mode at $400 \mathrm{~mA}$ and $2.4 \mathrm{GeV}$. The measurements were performed at the Ni K-edge $(8333 \mathrm{eV})$ in transmission mode. The polychromatic X-ray beam was collimated using a Si-coated mirror at $2.5 \mathrm{mrad}$ located in front of the monochromator. The monochromatized beam was focused to a beam size of $200 \mu \mathrm{m} \times 200 \mu \mathrm{m}$ at the sample position using a Rh-coated mirror at $2.5 \mathrm{mrad}$. A channel-cut $\mathrm{Si}(111)$ monochromator oscillating at $22 \mathrm{~Hz}$ was used together with $\mathrm{N}_{2}$-filled gridded ionization chambers both dedicated for fast data acquisition, where a Ni foil was measured simultaneously with the data for absolute energy calibration. In each oscillation of the monochromator, two spectra were recorded, one with increasing energy, another one with decreasing energy. With this system operando X-ray absorption spectroscopy (XAS) data were recorded with 44 spectra/s.

For the operando XAS experiments the catalyst sample was diluted with $\mathrm{Al}_{2} \mathrm{O}_{3}(1: 1)$ and placed into a 1.5-mm quartz glass capillary (100-200 $\mu \mathrm{m}$ sieved fraction, $10 \mathrm{mg}, 10 \mathrm{~mm}$ catalyst bed) and fixed with quartz wool plugs [72]. Spectra were acquired at the middle of the catalyst bed. The capillary-based reactor was connected to the gas dosing system equipped with individual mass flow controllers (Bronkhorst, Ruurlo, The Netherlands) and heated using a hot air blower (FMB Oxford GSB-1300, Oxford, UK) [73]. The total gas flow was adjusted to $20 \mathrm{~mL} / \mathrm{min}$ using similar compositions as in the laboratory experiments (reduction: $50 \% \mathrm{H}_{2} / \mathrm{He}$, methanation: $25 \%$ reactants $\left(\mathrm{H}_{2} / \mathrm{CO}_{2}=4\right)$ in $\mathrm{He}$ ). The same WHSV of $12,000 \mathrm{~mL}_{\mathrm{CO}_{2}} /\left(\mathrm{g}_{\mathrm{cat}} \cdot \mathrm{h}\right)$ as in the laboratory was used resulting in a higher GHSV of $71,700 \mathrm{~h}^{-1}$ due to the different dimensions of the reactor. Fast switches of the gas atmosphere were realized using a micro-electric VICI (Schenkon, Switzerland) 4-way valve. The gas composition was analyzed by a Pfeiffer Vacuum (Aßlar, Germany) ThermoStar ${ }^{\mathrm{TM}}$ GSD 320 mass spectrometer (MS) equipped with a quartz capillary and a C-SEM/Faraday detector.

The measurement of $44 \mathrm{spectra} / \mathrm{s}$ allowed detection of changes with a time resolution of $23 \mathrm{~ms}$. However, it was found that a 1-s time resolution was sufficient to monitor the structural changes of the catalyst, and thus, the spectra could be averaged for $1 \mathrm{~s}$ each to improve data quality. Matlab ${ }^{\circledR}$ (v8.6, The Mathworks Inc., Natick, MA, USA, 2015) routines were used for merging QEXAFS data to $1 \mathrm{~s} /$ spectrum, energy calibration to a metallic Ni foil, normalization and for conducting linear combination analysis (LCA). For the latter, a linear combination of reference spectra was fitted to the sample spectra in the XANES region (from $-30 \mathrm{eV}$ to $+50 \mathrm{eV}$ ). The spectrum of the reduced catalyst in $50 \% \mathrm{H}_{2} / \mathrm{He}$ atmosphere and of the oxidized catalyst in $5 \% \mathrm{O}_{2}$, both acquired at $400{ }^{\circ} \mathrm{C}$, were used as reduced and oxidized reference, respectively (see Figure S3). 
EXAFS data analysis was performed using Athena and Artemis of the IFEFFIT software package (v1.2.11, Chicago, IL, USA, 2008) [74] on spectra collected during steady state conditions and on selected spectra during fluctuating operation. In this case, 220 spectra were averaged, as this was sufficient to monitor the structural changes and improve the data quality $(5 \mathrm{~s} / \mathrm{spectrum})$. The theoretical data was adjusted to fit the experimental spectra by a least square method in Fourier-transformed (FT) EXAFS spectra (with $k^{1}-, k^{2}$ - and $k^{3}$-weighted EXAFS functions, FT EXAFS spectra, $k$ and R range, as well as fixed and varied parameters are shown in the Supplementary Materials) considering metallic $\mathrm{Ni}$ (ICSD: 64989) and $\mathrm{NiO}$ (ICSD: 9866). Corresponding backscattering amplitudes and phases were calculated with Feff 6.0 [75]. Amplitude reduction factors $\left(\mathrm{S}_{0}{ }^{2}\right)$ were obtained on metallic and NiO bulk references (more details, cf. the Supplementary Materials). Coordination number $(\mathrm{N})$, bond distance $(R)$ and energy alignment between theoretical and experimental data $\left(\Delta \mathrm{E}_{0}\right)$ were refined for each spectrum. The mean square deviation of interatomic distances $\left(\sigma^{2}\right)$ was obtained by simultaneously refining spectra of the sample in similar conditions and at the same temperature (cf. the Supplementary Materials).

\section{Conclusions}

Experiments with periodically changing atmospheres during the methanation of technical $\mathrm{CO}_{2}$ simulated as $\mathrm{H}_{2}$ dropouts were performed and resulted in detailed insights into the catalyst deactivation mechanism. During $\mathrm{H}_{2}$ interruptions, catalyst deactivation occurred due to oxidation of the most active surface $\mathrm{Ni}$ sites in the presence of $\mathrm{O}_{2}$ impurities (500-1000 ppm) in technical $\mathrm{CO}_{2}$. Thirty-second short-term $\mathrm{H}_{2}$ dropouts showed surface oxidation and reduction occurring after the seventh modulation cycle monitored in the center of the catalyst bed. The core of the Ni particles remained reduced, since full oxidation was interrupted. Nevertheless, catalyst deactivation occurred already after the first dropout since the oxidation of the active sites propagates stepwise through the catalyst bed starting from the reactor inlet. This gives important insight into the mechanism of the methanation reaction and, obviously, even short interruptions in the $\mathrm{H}_{2}$ feed, and thus, slight oxidation of the most active Ni sites cannot be tolerated by the catalyst. Therefore, it is important to prevent $\mathrm{H}_{2}$ dropouts in industrial methanation applications, where traces of $\mathrm{O}_{2}$ might be present. This can also be transferred to other power-to-chemicals processes using renewable $\mathrm{H}_{2}$. A higher impact on the deactivation was observed during 300-s modulation, where a bulk oxidation was observed even in the first $\mathrm{H}_{2}$ dropout, which resulted in a higher fraction of oxidized Ni remaining on the catalyst during the methanation sequence and, thus, an even lower $\mathrm{CH}_{4}$ production.

The presence of small amounts of oxygen in the $\mathrm{CO}_{2}$ stream can already block a small fraction of most active Ni sites, which had a strong influence on the $\mathrm{CO}_{2}$-methanation activity. This "titration" of active sites may be further used in future to understand the methanation of $\mathrm{CO}_{2}$, but also other $\mathrm{CO}_{2}$ hydrogenation mechanisms in more detail.

Supplementary Materials: The following are available online at www.mdpi.com/2073-4344/7/9/279/s1, Figure S1: XRD patterns of the $\gamma-\mathrm{Al}_{2} \mathrm{O}_{3}$ support and the $10 \mathrm{wt} \% \mathrm{Ni} / \mathrm{Al}_{2} \mathrm{O}_{3}$ catalyst in its oxidized and reduced state. Figure $\mathrm{S} 2: \mathrm{H}_{2}-\mathrm{TPR}$ profile of the $10 \mathrm{wt} \% \mathrm{Ni} / \mathrm{Al}_{2} \mathrm{O}_{3}$ catalyst. Figure S3: Reference XANES spectra of the bulk materials (recorded at room temperature) and in situ oxidized and reduced spectra of the catalyst (measured at $400^{\circ} \mathrm{C}$ ) for linear combination analysis (LCA). Figure S4: XANES and FT EXAFS spectra of the reduced catalyst in $\mathrm{H}_{2}$ / He at room temperature (RT) and at $400^{\circ} \mathrm{C}$ and in He atmosphere at $400^{\circ} \mathrm{C}$. Figure S5: Full-length experiment of the 30- $\mathrm{H}_{2}$ dropout modulations during methanation of $\mathrm{CO}_{2}$. Figure S6: Zoom of the first 6 min during the 30-s modulation. Figure S7: Zoom of the first 14 min during the 300-s $\mathrm{H}_{2}$ dropout modulation. Figures S8-S13: Experimental and simulated EXAFS data. Figures S14 and S15: Full MS dataset recorded during the 30-s and 300-s $\mathrm{H}_{2}$ dropout modulations, respectively. Figure S16: Comparison of the MS signals of $\mathrm{CH}_{4}(\mathrm{~m} / z$ 15) during the $30-\mathrm{s}$ and $300-\mathrm{s} \mathrm{H}_{2}$ dropout modulations. Figure S17: Sixty-second $\mathrm{H}_{2}$ modulation in an oxygen-free experiment. Figure S18: Series of 300-s $\mathrm{H}_{2}$ dropout periods during the methanation of $\mathrm{CO}_{2}$ containing $300-500 \mathrm{ppm} \mathrm{O}_{2}$. Tables S1-S5: Structural parameters of the local Ni atomic environment extracted from the EXAFS spectra. 
Acknowledgments: This work was funded and supported by Karlsruhe Institute of Technology (KIT) and the Helmholtz Research School "Energy-Related Catalysis". The Swiss Light Source (SLS) is acknowledged for providing beam time at the SuperXAS beamline and technical support. The infrastructure was funded within the BMBF projects "MatAkt" (05K10VKB), "ZeitKatMat" (05K13VK13, 05K13PX1) and MatDynamics (05K16PX1). The authors thank Di Wang and Sina Baier (STEM), Hermann Köhler (ICP-OES) and Angela Beilmann (BET).

Author Contributions: J.-D.G. and W.K. developed the topic with B.M. and A.M.G and supervised the experimental work. B.M. designed and characterized the catalyst and performed activity measurements. B.M. and A.M.G. performed the operando QEXAFS experiment. O.M. and M.N. contributed with technical and scientific support. O.M., R.F. and M.N. developed the QEXAFS setting at SLS. A.M.G. analyzed the EXAFS data supported by O.M. The manuscript was written with contributions from all authors.

Conflicts of Interest: The authors declare no conflict of interest.

\section{References}

1. Schüth, F. Chemical Compounds for Energy Storage. Chem. Ing. Technol. 2011, 83, 1984-1993. [CrossRef]

2. Schlögl, R. Chemical Energy Storage; Walter de Gruyter GmbH: Berlin, Germany; Boston, MA, USA, 2013.

3. Sterner, M. Erneuerbare Energien und Energieeffizienz-Renewable Energies and Energy Efficiency; Kassel University Press GmbH: Kassel, Germany, 2009; Volume 14.

4. Hashimoto, K.; Yamasaki, M.; Fujimura, K.; Matsui, T.; Izumiya, K.; Komori, M.; El-Moneim, A.A.; Akiyama, E.; Habazaki, H.; Kumagai, N.; et al. Global $\mathrm{CO}_{2}$ recycling-Novel materials and prospect for prevention of global warming and abundant energy supply. Mater. Sci. Eng. A 1999, 267, $200-206$. [CrossRef]

5. Kalz, K.F.; Kraehnert, R.; Dvoyashkin, M.; Dittmeyer, R.; Gläser, R.; Krewer, U.; Reuter, K.; Grunwaldt, J.-D. Future Challenges in Heterogeneous Catalysis: Understanding Catalysts under Dynamic Reaction Conditions. Chem. Cat. Chem. 2017, 9, 17-29. [CrossRef] [PubMed]

6. Götz, M.; Lefebvre, J.; Mörs, F.; McDaniel Koch, A.; Graf, F.; Bajohr, S.; Reimert, R.; Kolb, T. Renewable Power-to-Gas: A technological and economic review. Renew. Energy 2016, 85, 1371-1390. [CrossRef]

7. Iglesias González, M.; Schaub, G. Fischer-Tropsch Synthesis with $\mathrm{H}_{2} / \mathrm{CO}_{2}$-Catalyst Behavior under Transient Conditions. Chem. Ing. Technol. 2015, 87, 848-854. [CrossRef]

8. Iglesias González, M.; Eilers, H.; Schaub, G. Flexible Operation of Fixed-Bed Reactors for a Catalytic Fuel Synthesis- $\mathrm{CO}_{2}$ Hydrogenation as Example Reaction. Energy Technol. 2016, 4, 90-103. [CrossRef]

9. Gao, J.; Liu, Q.; Gu, F.; Liu, B.; Zhong, Z.; Su, F. Recent advances in methanation catalysts for the production of synthetic natural gas. RSC Adv. 2015, 5, 22759-22776. [CrossRef]

10. Aziz, M.A.A.; Jalil, A.A.; Triwahyono, S.; Ahmad, A. $\mathrm{CO}_{2}$ methanation over heterogeneous catalysts: Recent progress and future prospects. Green Chem. 2015, 17, 2647-2663. [CrossRef]

11. Aziz, M.A.A.; Jalil, A.A.; Triwahyono, S.; Mukti, R.R.; Taufiq-Yap, Y.H.; Sazegar, M.R. Highly active Ni-promoted mesostructured silica nanoparticles for $\mathrm{CO}_{2}$ methanation. Appl. Catal. B 2014, 147, 359-368. [CrossRef]

12. Bian, L.; Zhang, L.; Xia, R.; Li, Z. Enhanced low-temperature $\mathrm{CO}_{2}$ methanation activity on plasma-prepared Ni-based catalyst. J. Nat. Gas Sci. Eng. 2015, 27, 1189-1194. [CrossRef]

13. Liu, J.; Li, C.; Wang, F.; He, S.; Chen, H.; Zhao, Y.; Wei, M.; Evans, D.G.; Duan, X. Enhanced low-temperature activity of $\mathrm{CO}_{2}$ methanation over highly-dispersed Ni/TiO 2 catalyst. Catal. Sci. Technol. 2013, 3, 2627-2633. [CrossRef]

14. Ocampo, F.; Louis, B.; Roger, A.-C. Methanation of carbon dioxide over nickel-based $\mathrm{Ce}_{0.72} \mathrm{Zr}_{0.28} \mathrm{O}_{2}$ mixed oxide catalysts prepared by sol-gel method. Appl. Catal. A 2009, 369, 90-96. [CrossRef]

15. Rahmani, S.; Rezaei, M.; Meshkani, F. Preparation of highly active nickel catalysts supported on mesoporous nanocrystalline $\gamma-\mathrm{Al}_{2} \mathrm{O}_{3}$ for $\mathrm{CO}_{2}$ methanation. J. Ind. Eng. Chem. 2014, 20, 1346-1352. [CrossRef]

16. Tada, S.; Shimizu, T.; Kameyama, H.; Haneda, T.; Kikuchi, R. Ni/CeO 2 catalysts with high $\mathrm{CO}_{2}$ methanation activity and high $\mathrm{CH}_{4}$ selectivity at low temperatures. Int. J. Hydrogen Energy 2012, 37, 5527-5531. [CrossRef]

17. He, S.; Li, C.; Chen, H.; Su, D.; Zhang, B.; Cao, X.; Wang, B.; Wei, M.; Evans, D.G.; Duan, X. A Surface Defect-Promoted Ni Nanocatalyst with Simultaneously Enhanced Activity and Stability. Chem. Mater. 2013, 25, 1040-1046. [CrossRef]

18. Li, Y.; Zhang, Q.; Chai, R.; Zhao, G.; Liu, Y.; Lu, Y.; Cao, F. Ni- $\mathrm{Al}_{2} \mathrm{O}_{3} / \mathrm{Ni}$-foam catalyst with enhanced heat transfer for hydrogenation of $\mathrm{CO}_{2}$ to methane. AlChE J. 2015, 61, 4323-4331. [CrossRef] 
19. Garbarino, G.; Bellotti, D.; Riani, P.; Magistri, L.; Busca, G. Methanation of carbon dioxide on $\mathrm{Ru} / \mathrm{Al}_{2} \mathrm{O}_{3}$ and $\mathrm{Ni} / \mathrm{Al}_{2} \mathrm{O}_{3}$ catalysts at atmospheric pressure: Catalysts activation, behaviour and stability. Int. J. Hydrogen Energy 2015, 40, 9171-9182. [CrossRef]

20. Abe, T.; Tanizawa, M.; Watanabe, K.; Taguchi, A. $\mathrm{CO}_{2}$ methanation property of Ru nanoparticle-loaded $\mathrm{TiO}_{2}$ prepared by a polygonal barrel-sputtering method. Energy Environ. Sci. 2009, 2, 315-321. [CrossRef]

21. Hoekman, S.K.; Broch, A.; Robbins, C.; Purcell, R. $\mathrm{CO}_{2}$ recycling by reaction with renewably-generated hydrogen. Int. J. Greenh. Gas Control 2010, 4, 44-50. [CrossRef]

22. Mutz, B.; Carvalho, H.W.P.; Mangold, S.; Kleist, W.; Grunwaldt, J.-D. Methanation of $\mathrm{CO}_{2}$ : Structural response of a Ni-based catalyst under fluctuating reaction conditions unraveled by operando spectroscopy. J. Catal. 2015, 327, 48-53. [CrossRef]

23. Aldana, P.A.U.; Ocampo, F.; Kobl, K.; Louis, B.; Thibault-Starzyk, F.; Daturi, M.; Bazin, P.; Thomas, S.; Roger, A.C. Catalytic $\mathrm{CO}_{2}$ valorization into $\mathrm{CH}_{4}$ on Ni-based ceria-zirconia. Reaction mechanism by operando IR spectroscopy. Catal. Today 2013, 215, 201-207. [CrossRef]

24. Zarfl, J.; Ferri, D.; Schildhauer, T.J.; Wambach, J.; Wokaun, A. DRIFTS study of a commercial Ni/ $\gamma-\mathrm{Al}_{2} \mathrm{O}_{3} \mathrm{CO}$ methanation catalyst. Appl. Catal. A 2015, 495, 104-114. [CrossRef]

25. Rönsch, S.; Köchermann, J.; Schneider, J.; Matthischke, S. Global Reaction Kinetics of $\mathrm{CO}$ and $\mathrm{CO}_{2}$ Methanation for Dynamic Process Modeling. Chem. Eng. Technol. 2016, 39, 208-218. [CrossRef]

26. Rönsch, S.; Matthischke, S.; Müller, M.; Eichler, P. Dynamische Simulation von Reaktoren zur Festbettmethanisierung-Dynamic Simulation of Fixed-Bed Methanation Reactors. Chem. Ing. Technol. 2014, 86, 1198-1204. [CrossRef]

27. Eilers, H.; Schaub, G. Fischer-Tropsch-Synthese unter instationären Bedingungen im Suspensionsreaktor: Experimentelle und rechnerische Studien-Fischer-Tropsch Synthesis under Transient Conditions in a Slurry Reactor: Experimental and Mathematical Investigations. Chem. Ing. Technol. 2015, 87, 837-842. [CrossRef]

28. Newton, M.A. Dynamic adsorbate/reaction induced structural change of supported metal nanoparticles: Heterogeneous catalysis and beyond. Chem. Soc. Rev. 2008, 37, 2644-2657. [CrossRef] [PubMed]

29. Stötzel, J.; Frahm, R.; Kimmerle, B.; Nachtegaal, M.; Grunwaldt, J.-D. Oscillatory Behavior during the Catalytic Partial Oxidation of Methane: Following Dynamic Structural Changes of Palladium Using the QEXAFS Technique. J. Phys. Chem. C 2012, 116, 599-609. [CrossRef]

30. Grunwaldt, J.-D.; Molenbroek, A.M.; Topsøe, N.Y.; Topsøe, H.; Clausen, B.S. In Situ Investigations of Structural Changes in Cu/ZnO Catalysts. J. Catal. 2000, 194, 452-460. [CrossRef]

31. Hansen, P.L.; Wagner, J.B.; Helveg, S.; Rostrup-Nielsen, J.R.; Clausen, B.S.; Topsøe, H. Atom-resolved imaging of dynamic shape changes in supported copper nanocrystals. Science 2002, 295, 2053-2055. [CrossRef] [PubMed]

32. Gänzler, A.M.; Casapu, M.; Boubnov, A.; Müller, O.; Conrad, S.; Lichtenberg, H.; Frahm, R.; Grunwaldt, J.-D. Operando spatially and time-resolved $\mathrm{X}$-ray absorption spectroscopy and infrared thermography during oscillatory CO oxidation. J. Catal. 2015, 328, 216-224. [CrossRef]

33. Eslava, J.L.; Iglesias-Juez, A.; Agostini, G.; Fernández-García, M.; Guerrero-Ruiz, A.; Rodríguez-Ramos, I. Time-Resolved XAS Investigation of the Local Environment and Evolution of Oxidation States of a Fischer-Tropsch Ru-Cs/C Catalyst. ACS Catal. 2016, 6, 1437-1445. [CrossRef]

34. Mutz, B.; Carvalho, H.W.P.; Kleist, W.; Grunwaldt, J.-D. Dynamic transformation of small Ni particles during methanation of $\mathrm{CO}_{2}$ under fluctuating reaction conditions monitored by operando X-ray absorption spectroscopy. J. Phys. Conf. Ser. 2016, 712, 012050. [CrossRef]

35. Abbas, Z.; Mezher, T.; Abu-Zahra, M.R.M. Evaluation of $\mathrm{CO}_{2}$ Purification Requirements and the Selection of Processes for Impurities Deep Removal from the $\mathrm{CO}_{2}$ Product Stream. Energy Procedia 2013, 37, 2389-2396. [CrossRef]

36. Köppel, W.; Götz, M.; Graf, F. Biogas upgrading for injection into the gas grid. Gwf-Gas Erdgas. 2009, 150, 26-35.

37. Burattin, P.; Che, M.; Louis, C. Metal Particle Size in $\mathrm{Ni}^{-} \mathrm{SiO}_{2}$ Materials Prepared by Deposition-Precipitation: Influence of the Nature of the Ni(II) Phase and of Its Interaction with the Support. J. Phys. Chem. B 1999, 103, 6171-6178. [CrossRef]

38. Bitter, J.H.; van der Lee, M.K.; Slotboom, A.G.T.; van Dillen, A.J.; de Jong, K.P. Synthesis of Highly Loaded Highly Dispersed Nickel on Carbon Nanofibers by Homogeneous Deposition-Precipitation. Catal. Lett. 2003, 89, 139-142. [CrossRef] 
39. Garbarino, G.; Riani, P.; Magistri, L.; Busca, G. A study of the methanation of carbon dioxide on $\mathrm{Ni} / \mathrm{Al}_{2} \mathrm{O}_{3}$ catalysts at atmospheric pressure. Int. J. Hydrogen Energy 2014, 39, 11557-11565. [CrossRef]

40. Jung, Y.-S.; Yoon, W.-L.; Lee, T.-W.; Rhee, Y.-W.; Seo, Y.-S. A highly active Ni- $\mathrm{Al}_{2} \mathrm{O}_{3}$ catalyst prepared by homogeneous precipitation using urea for internal reforming in a molten carbonate fuel cell (MCFC): Effect of the synthesis temperature. Int. J. Hydrogen Energy 2010, 35, 11237-11244. [CrossRef]

41. Seo, J.G.; Youn, M.H.; Park, D.R.; Nam, I.; Song, I.K. Hydrogen production by steam reforming of liquefied natural gas (LNG) over $\mathrm{Ni}-\mathrm{Al}_{2} \mathrm{O}_{3}$ catalysts prepared by a sequential precipitation method: Effect of precipitation agent. Int. J. Hydrogen Energy 2009, 34, 8053-8060. [CrossRef]

42. Gao, J.; Wang, Y.; Ping, Y.; Hu, D.; Xu, G.; Gu, F.; Su, F. A thermodynamic analysis of methanation reactions of carbon oxides for the production of synthetic natural gas. RSC Adv. 2012, 2, 2358-2368. [CrossRef]

43. Xu, L.; Wang, F.; Chen, M.; Zhang, J.; Yuan, K.; Wang, L.; Wu, K.; Xu, G.; Chen, W. CO 2 methanation over a Ni based ordered mesoporous catalyst for the production of synthetic natural gas. RSC Adv. 2016, 6, 28489-28499. [CrossRef]

44. Frahm, R. Quick scanning EXAFS: First experiments. Nucl. Instrum. Methods Phys. Res. Sect. A 1988, 270, 578-581. [CrossRef]

45. Frahm, R. New method for time dependent X-ray absorption studies. Rev. Sci. Instrum. 1989, 60, $2515-2518$. [CrossRef]

46. Nachtegaal, M.; Müller, O.; König, C.; Frahm, R. QEXAFS: Techniques and Scientific Applications for Time-Resolved XAS. In X-ray Absorption and X-ray Emission Spectroscopy; van Bokhoven, J.A., Lamberti, C., Eds.; Wiley-VCH: Weinheim, Germany, 2016; pp. 155-183.

47. Doronkin, D.E.; Casapu, M.; Günter, T.; Müller, O.; Frahm, R.; Grunwaldt, J.-D. Operando Spatially- and Time-Resolved XAS Study on Zeolite Catalysts for Selective Catalytic Reduction of $\mathrm{NO}_{X}$ by $\mathrm{NH}_{3}$. J. Phys. Chem. C 2014, 118, 10204-10212. [CrossRef]

48. Abild-Pedersen, F.; Lytken, O.; Engbæk, J.; Nielsen, G.; Chorkendorff, I.; Nørskov, J.K. Methane activation on $\mathrm{Ni}(111)$ : Effects of poisons and step defects. Surf. Sci. 2005, 590, 127-137. [CrossRef]

49. Molenbroek, A.M.; Nørskov, J.K.; Clausen, B.S. Structure and Reactivity of Ni-Au Nanoparticle Catalysts. J. Phys. Chem. B 2001, 105, 5450-5458. [CrossRef]

50. Vang, R.T.; Honkala, K.; Dahl, S.; Vestergaard, E.K.; Schnadt, J.; Laegsgaard, E.; Clausen, B.S.; Norskov, J.K.; Besenbacher, F. Controlling the catalytic bond-breaking selectivity of Ni surfaces by step blocking. Nat. Mater. 2005, 4, 160-162. [CrossRef] [PubMed]

51. Bengaard, H.S.; Nørskov, J.K.; Sehested, J.; Clausen, B.S.; Nielsen, L.P.; Molenbroek, A.M.; Rostrup-Nielsen, J.R. Steam Reforming and Graphite Formation on Ni Catalysts. J. Catal. 2002, 209, 365-384. [CrossRef]

52. Kirstein, W.; Petraki, I.; Thieme, F. A study on oxygen adsorption and coadsorption with carbonmonoxide on a stepped nickel surface. Surf. Sci. 1995, 331, 162-167. [CrossRef]

53. Marwood, M.; Doepper, R.; Renken, A. In-situ surface and gas phase analysis for kinetic studies under transient conditions The catalytic hydrogenation of $\mathrm{CO}_{2}$. Appl. Catal. A 1997, 151, 223-246. [CrossRef]

54. Pan, Q.; Peng, J.; Sun, T.; Wang, S.; Wang, S. Insight into the reaction route of $\mathrm{CO}_{2}$ methanation: Promotion effect of medium basic sites. Catal. Commun. 2014, 45, 74-78. [CrossRef]

55. Andersson, M.P.; Abild-Pedersen, F.; Remediakis, I.N.; Bligaard, T.; Jones, G.; Engbæk, J.; Lytken, O.; Horch, S.; Nielsen, J.H.; Sehested, J.; et al. Structure sensitivity of the methanation reaction: $\mathrm{H}_{2}$-induced CO dissociation on nickel surfaces. J. Catal. 2008, 255, 6-19. [CrossRef]

56. Holloway, P.H. Chemisorption and oxide formation on metals: Oxygen-nickel reaction. J. Vac. Sci. Technol. 1981, 18, 653-659. [CrossRef]

57. Besenbacher, F.; Nørskov, J.K. Oxygen chemisorption on metal surfaces: General trends for Cu, Ni and Ag. Prog. Surf. Sci. 1993, 44, 5-66. [CrossRef]

58. Dahl, S.; Logadottir, A.; Egeberg, R.; Larsen, J.; Chorkendorff, I.; Törnqvist, E.; Nørskov, J.K. Role of steps in $\mathrm{N}_{2}$ activation on $\mathrm{Ru}(0001)$. Phys. Rev. Lett. 1999, 83, 1814. [CrossRef]

59. Gracia, F.J.; Bollmann, L.; Wolf, E.E.; Miller, J.T.; Kropf, A.J. In situ FTIR, EXAFS, and activity studies of the effect of crystallite size on silica-supported Pt oxidation catalysts. J. Catal. 2003, 220, 382-391. [CrossRef]

60. Kale, M.J.; Christopher, P. Utilizing Quantitative in Situ FTIR Spectroscopy To Identify Well-Coordinated Pt Atoms as the Active Site for CO Oxidation on $\mathrm{Al}_{2} \mathrm{O}_{3}$-Supported Pt Catalysts. ACS Catal. 2016, 6, 5599-5609. [CrossRef] 
61. Boubnov, A.; Gänzler, A.; Conrad, S.; Casapu, M.; Grunwaldt, J.-D. Oscillatory CO Oxidation Over Pt/ $\mathrm{Al}_{2} \mathrm{O}_{3}$ Catalysts Studied by In situ XAS and DRIFTS. Top. Catal. 2013, 56, 333-338. [CrossRef]

62. Jacobsen, C.J.H.; Dahl, S.; Hansen, P.L.; Törnqvist, E.; Jensen, L.; Topsøe, H.; Prip, D.V.; Møenshaug, P.B.; Chorkendorff, I. Structure sensitivity of supported ruthenium catalysts for ammonia synthesis. J. Mol. Catal. A Chem. 2000, 163, 19-26. [CrossRef]

63. Van Hardeveld, R.; van Montfoort, A. The influence of crystallite size on the adsorption of molecular nitrogen on nickel, palladium and platinum. Surf. Sci. 1966, 4, 396-430. [CrossRef]

64. Mortensen, P.M.; Grunwaldt, J.-D.; Jensen, P.A.; Jensen, A.D. Influence on nickel particle size on the hydrodeoxygenation of phenol over $\mathrm{Ni} / \mathrm{SiO}_{2}$. Catal. Today 2016, 259, 277-284. [CrossRef]

65. Benfield, R.E. Mean coordination numbers and the non-metal-metal transition in clusters. J. Chem. Soc. Faraday Trans. 1992, 88, 1107-1110. [CrossRef]

66. Geus, J.W.; van Dillen, A.J. Preparation of Supported Catalysts by Deposition-Precipitation. In Handbook of Heterogeneous Catalysis; Ertl, G., Knözinger, H., Schüth, F., Weitkamp, J., Eds.; Wiley-VCH: Weinheim, Germany, 2008; pp. 428-467.

67. De Jong, K.P. Deposition Precipitation. In Synthesis of Solid Catalysts; de Jong, K.P., Ed.; Wiley-VCH: Weinheim, Germany, 2009; pp. 111-134.

68. Van der Lee, M.K.; van Dillen, J.; Bitter, J.H.; de Jong, K.P. Deposition Precipitation for the Preparation of Carbon Nanofiber Supported Nickel Catalysts. JACS 2005, 127, 13573-13582. [CrossRef] [PubMed]

69. Bergeret, G.; Gallezot, P. Particle Size and Dispersion Measurements. In Handbook of Heterogeneous Catalysis; Ertl, G., Knözinger, H., Schüth, F., Weitkamp, J., Eds.; Wiley-VCH: Weinheim, Germany, 2008; pp. 738-765.

70. Müller, O.; Nachtegaal, M.; Just, J.; Lutzenkirchen-Hecht, D.; Frahm, R. Quick-EXAFS setup at the SuperXAS beamline for in situ X-ray absorption spectroscopy with $10 \mathrm{~ms}$ time resolution. J. Synchrotron. Radiat. 2016, 23, 260-266. [CrossRef] [PubMed]

71. Müller, O.; Lützenkirchen-Hecht, D.; Frahm, R. Quick scanning monochromator for millisecond in situ and in operando X-ray absorption spectroscopy. Rev. Sci. Instrum. 2015, 86, 093905. [CrossRef] [PubMed]

72. Grunwaldt, J.-D.; van Vegten, N.; Baiker, A. Insight into the structure of supported palladium catalysts during the total oxidation of methane. Chem. Commun. 2007, 4635-4637. [CrossRef] [PubMed]

73. Grunwaldt, J.-D.; Caravati, M.; Hannemann, S.; Baiker, A. X-ray absorption spectroscopy under reaction conditions: Suitability of different reaction cells for combined catalyst characterization and time-resolved studies. Phys. Chem. Chem. Phys. 2004, 6, 3037-3047. [CrossRef]

74. Ravel, B.; Newville, M. Athena, Artemis, Hephaestus: Data analysis for X-ray absorption spectroscopy using IFEFFIT. J. Synchrotron. Radiat. 2005, 12, 537-541. [CrossRef] [PubMed]

75. Rehr, J.J.; Albers, R. Theoretical approaches to X-ray absorption fine structure. Rev. Mod. Phys. 2000, $72,621$. [CrossRef]

(c) 2017 by the authors. Licensee MDPI, Basel, Switzerland. This article is an open access article distributed under the terms and conditions of the Creative Commons Attribution (CC BY) license (http:/ / creativecommons.org/licenses/by/4.0/). 